\title{
Metal organic framework (MOF) liquid crystals. 1D, 2D and 3D ionic coordination polymer structures in the thermotropic mesophases of metal soaps, including alkaline earth, transition metal and lanthanide soaps
}

\author{
Robert W. Corkery * \\ Applied Mathematics Research School of Physical Sciences and Engineering Australian National University, Canberra ACT 0200, Australia
}

\section{A R T I C L E I N F O}

\section{Article history:}

Received 28 January 2008

Accepted 11 March 2008

Available online 10 April 2008

\begin{abstract}
A B S T R A C T
Taken together, the body of existing literature on metal soap crystal structures and mesophases supports the view that much is to be gained by treating the soaps as metal organic frameworks (MOF's) when relating their structure and liquid crystallinity.

We argue that metal soaps mesophases often consist of disordered metal organic (carboxylate) frameworks (MOF's). Metal atoms are linked by bridging carboxylates, and the metal-oxygen networks form semi-flexible rods, chains and sheets of $\mathrm{M}-\mathrm{O}$ polyhedra within their co-bonded, mesotructured, self-assemblies of lipidic chains. The packing of the molten hydrocarbon chains allows otherwise unconnected MOF networks to coexist as spatially isolated units in the same unit cell. For instance the lamellar phases are true 2D MOF's or layers of 1-D MOF's. The phase transitions can then be regarded as coupled disordering/re-ordering transitions involving rotational and conformational disordering of the hydrocarbon chains balanced with disordering of MOF symmetries, MOF topological transformations, depolymerizations and dimensionality reductions ultimately leading to anisotropic melts.

By way of demonstration, thermotropic phase transitions of homologous series of lanthanide soaps are systematically studied using a variety of experimental methods, and the data are used in a topological model for testing the consistency with the MOF concept of metal soap crystal structures and thermotropic mesophases. Finally, an interpenetrating bicontinuous $\mathrm{MOF}$ comprised of $\mathrm{SrO}_{6}$ polyhedral rods is presented as an atomically resolved model for the network topology of the cubic mesophase of strontium soaps. Metal soaps are therefore shown to afford a bridge between liquid crystals and metal organic framework (MOF) materials.
\end{abstract}

(C) 2008 Published by Elsevier Ltd.

\section{Introduction}

The first observation of mesomorphism in soaps was arguably by Heintz [ $\left.1^{\circ}\right]$, who described the mesomorphism of magnesium myristate. The thermotropic phase behaviour of the metallic soaps was firmly founded by Vorländer [2], who showed "double-melting" in many sodium and potassium soaps, using a polarising microscope [3]. Prior to about 1950, further work on thermotropic mesomorphism in soaps and analogs seems to have been concentrated on the phases of the sodium and potassium soaps, with some exceptions [4-13].

A significant advance in understanding liquid crystallinity in lipid containing systems was the realization that lipid chains are in the molten state in micellar and lamellar lipid-assemblies $\left[14^{\circ}, 15^{\circ}\right]$, overturning the established view (from the schools of McBain and Harkins) that the hydrocarbon chains were always rigid and parallel. This was a crucial physical concept that underpinned later seminal work on the structure and mesomorphism of lipidic systems, including the metal soaps, by Luzzati and colleagues from the late 1950's.

Arguably the most beautiful, and, for present purposes, most illustrative structures solved by Luzzati et al. are their high temperature alkaline earth and cadmium soap mesophases, consisting of 1D, 2D and 3D arrangements of "highly ordered" metal atoms on rod frameworks [16-18**] that occupy special positions of the respective space groups under which they were solved. Luzzati et al. presented overwhelming evidence that the linear cation density in the rods was nearly constant at $0.5 \AA^{-1}$, for the $1 \mathrm{D}, 2 \mathrm{D}$ and 3D mesophase structures of strontium soaps independent of variations in temperature and chain length. Similar constancy of cation densities on the rods was found in the other 1D, 2D and 3D frameworks in the magnesium, calcium, and cadmium soaps. These remarkable observations clearly demonstrated not only fixed metal-oxygen bond distances within their rather ionic frameworks of rather disordered mesophases, but absolutely constrains these inter-metal distances to dimensions where coordination polymers 
are highly likely to be stabilized via various bridging and chelating modes of carboxylate groups.

Many other accounts of thermotropic mesomorphism in metal soaps have been reported [19-26-32], and it is the general consensus that the existence of liquid crystallinity is owed, in part, to the cohesive inter-headgroup attractive forces associated with relatively thermally stable, predominantly ionic $\mathrm{M}-\mathrm{O}$ bonds; i.e., chain or sheet-like linkages. Another classic case is the crystal to liquid crystal transition of copper soaps. Here 2D lamellar crystalline soaps comprised of 2D packings of infinite $1 \mathrm{D}$ coordination polymers (axially coordinated $\mathrm{Cu}-$ $\mathrm{Cu}$ paddle-wheel dimers), transition to inverse hexagonal mesophases comprised of discrete, infinite 1D coordination polymers. Both the crystalline and liquid crystalline phases have essentially the same MOF bonding topology [33].

The observed ionic conduction ability of some metal soap mesophases and melts $[34,35]$ indicates that the polymeric nature is to some degree transient. However Luzzati's important observation[18**] of constant cation densities in alkaline earth soap mesophases, independent of phase and temperature, suggests that at any given instant, many particular soap systems probably have rather cohesive, though flexible polymeric MOF-like chains or sheets comprising their polar parts.

Regarding the relatively recent discovery of thermotropic mesomorphism in lanthanide soaps, it is surprising that neither Lawrence [36"] nor Vold and Vold [13] included a single rare earth soap in their comprehensive early studies of thermal transitions in metal soaps despite knowledge of cerium soaps at that time [37]. Later, Mehrotra and coworkers concentrated their work upon the synthesis and characterisation of the lanthanide soaps and their behavior in organic solvents [38-41]. Only during the last decade has the liquid crystallinity of lanthanide soaps been reported $\left[42^{*}-46^{*}, 47^{*}, 48^{\circ}-52^{*}\right]$ and their respective findings are generally in agreement with the work that forms the basis of the experimental work presented later in this paper [53*]. Collectively, these authors demonstrate that saturated soaps of lighter lanthanide elements have a tendency to display liquid crystallinity, while saturated soaps of the heavier lanthanide elements do not, the differential behavior ultimately attributed to the relatively smaller size of the latter elements. One or two smectic ('SmA2') molten-chain mesophases can occur in the progression to melting from the crystal in saturated soaps of the larger lanthanide ions ( $\mathrm{La}-$ $\mathrm{Nd}$ ) and hexagonal mesophases have been observed in the branchedchain lanthanide soaps [52].

Corkery's 1998 PhD thesis examined metal soaps in detail, and in particular lanthanide soaps. The current paper builds upon and updates the data interpretation of that first published account. In the present work, more subtle changes in the state of the hydrocarbon chains, and their rotational and conformational state and the relationship with the metal-oxygen frameworks are examined. Consequently a more general model for the transitions in lanthanide soaps (and metal soaps in general) is presented in terms of the interplay between hydrocarbon chain disorder and metal-oxygen framework (MOF) topology. MOFs are a class of materials comprised of organic linkers that bridge metals into a framework of struts and joints. The linkers and joints can be varied to give an enormous variety of structures, with various technological applications, and can be designed and classified according to the rules of reticular chemistry [54-60*].

\section{Structure in short-chain analogs of metal soaps}

Ionic polymer networks of pure lanthanide carboxylates and their hydrates are known from non-lamellar crystal structures of their acetates[61,62]. However, for understanding lanthanide soap crystal structures, short-chained layered butyrates appear to be homologous $\left[46^{*}, 47^{*}, 63^{* *}\right]$. The hydrated La and Nd butyrates are comprised of 1-D zig-zag chains of face-sharing, $\mathrm{MO}_{9}$ polyhedra, and these in turn form sheets via carboxylate bridging across chains, the sheets stack to form lamellar phases. These sheets are sandwiched between monolayers of fatty acids extending out on either side of the polar layers. A linear relationship between the inter-lamellar spacings of the short-chain analogs and the longchain soaps is evidence of the homology.

Further, this use of short-chain (monacid and diacid) analogs appears to be a previously unreported generalizable result for understanding metal soap crystal structures. For example, consider calcium stearate monohydrate, whose crystal structure has not yet been solved.

Lelann and Berár [64] used synchrotron X-ray scattering to get a partial solution for the structure of calcium steratate monohydrate, but they did not fully solve the network topology of Ca-carboxylate bonding in the polar layer. Charbonnier (1977) and Valor et al. (2002) reported the unit cells for short-chain calcium carboxylate monohydrates. The unit cells determined for these respective structures all share the same show the in-plane unit cell dimensions ( $b=6.81-6.82, c=5.89-5.93 \AA$ ), while the $a$ - dimension grows as a function of the chain length. Indeed Valor et al. plotted the long spacings as a function of chain length and concluded these were probably homologues, but did not have atomic resolution of the Ca-carboxylate network topology. The crystal structure of calcium adipate monohydrate (Mathew et al., 1993) resolves this problem, since their structure also has the same in-plane unit cell dimensions as found for calcium propionate, butyrate, valerate and caproate and stearate.

From the structure of calcium adipate monohydrate[65*3 we can now infer the structure of calcium stearate monohydrate (for example) has calcium ions in 7-coordination, linked together into chains via edge sharing and these chains linked into layers by bridging carboxylates and these layers separated by monolayers of fatty acid chains extending either side of the polar layer. Likewise, $\mathrm{Fe}, \mathrm{Cu}, \mathrm{Zn}, \mathrm{Pb}$, and other soaps also have layered short-chain homologues (including diacids) $\left[66,67^{\circ}, 68^{\circ *}-73\right]$. These results complement the extremely limited literature reporting metal-oxygen framework topology in long-chain metal soap crystal structures $\left[74,75^{*}\right]$.

Therefore we can confidently state that most of the saturated metal soaps will be lamellar crystals with various degrees of coordination polymer formation in the headgroup plane, the type of polymer heavily dependent on both ionic radius and coordination style of particular elements. This will impact the thermotropic phase transitions from the crystal to the melt. It is beyond the scope here to discuss the details of general metal soap structure and mesomorphism. However, the coordination-polymeric nature of the polar groups is salient to the present discussion of lanthanide soaps.

The polymeric nature is a direct result of the relatively large coordination numbers (up to 9) of the lanthanides, particularly the lighter, larger lanthanide ions. In pure anhydrous soaps, each metal requires three carboxylates for charge balancing, but this only results in a coordination number of six if three carboxylates remain on one metal atom only. The undersaturated coordination can only be balanced by oxygen sharing between metals and bridging. This is why they are more polymeric in the lighter and less polymeric in the heavier lanthanides. Further, water of hydration can enter and satisfy various other topological arrangements in the metal-oxygen networks of the headgroups. Therefore one layer of a lanthanide soap lamellar phase is comprised of 1D or more likely 2D metal organic framework polymers with aliphatic chains as branches.

Lanthanide soaps of saturated, long-chain fatty acids crystallize as lamellar phases, though with significant disorder, particularly the anhydrous soaps, while the hydrates and well-crystallized anhydrous soaps can show additional diffraction peaks, likely arising from the ( $h k 0)$ planes of the metal-oxygen networks and possibly ( $h k l)$ planes, 


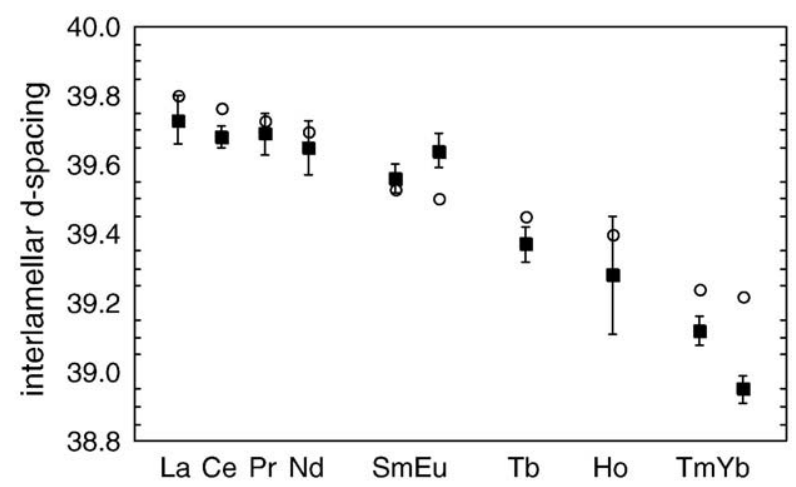

Fig. 1. Lanthanide contraction in the crystalline lanthanide soaps. Open circles are model $d$-spacings and the solid squares are measured $d$-spacings determined using powder X-ray diffraction (see text below). Data for Nd soap after Mehrotra et al. [40].

in addition to the usual long spacings and wide-angle hydrocarbon chain-packing peaks $\left[39,42^{*}, 46^{*}, 53^{*}\right]$. Fig. 1 shows the lanthanide contraction for the long-spacing of the lanthanide myristates [76].

Constraints on the metal coordination environments in lanthanide soaps using these spacings together with structural information from lanthanide butyrate $\left[46^{\circ}, 47^{*}\right]$ allow a division of lanthanide soaps, into isotypical sets across the period. For model calculations, the coordination numbers used are as follows: La-Nd -9 ; $\mathrm{Sm}-\mathrm{Ho}-8$; $\mathrm{Tm}-\mathrm{Yb}-7$ [76]. The crystalline lanthanide soaps are therefore likely to have metals with the following coordination numbers; La-Nd: 9- coordinate; Sm-Tm: 7-8-coordinated; and Yb, Lu: 6-7 coordinated. It is significant that the analogous acetates and butyrates can form 1D and 2D coordination polymers $\left[46^{\circ}, 47^{\circ}\right]$, because these metaloxygen polyhedral chains and sheets will place boundary conditions on the liquid-crystalline transition behavior. Indeed the same grouping of lanthanides is maintained when their liquid crystallinity is examined (Figs. 2 and 3).

\section{Liquid crystallinity of the lanthanide soaps}

3.1. Thermal history, hydration and the general phase transition sequence in the lanthanide soaps

Metal soaps, in particular the fatty acid-rich lanthanide soaps, often crystallize from solvents or from above their chain-melting temperature with large amounts of disorder compared to smaller molecules, and with varying degrees of hydration. Anhydrous soaps will re-uptake water to form hemi- and monohydrates. It is generally well known that thermal history can affect their respective phase progression enthalpies and transition temperatures measured using calorimetry, primarily due to dehydration and trapping disorder in room temperature crystalline phases $\left[42{ }^{*}, 46 *, 53^{*}, 77^{\circ}, 78\right]$. Significantly higher heats of fusion are found for samples whose thermal history has not included melt re-crystallization (i.e., from a fully molten-chain state, either liquid or liquid crystalline) and or dehydration. For example the heat of fusion for the air-dried myristates of praseodymium, samarium, terbium and thulium are similar and all significantly higher than heats of fusion for "glassy",
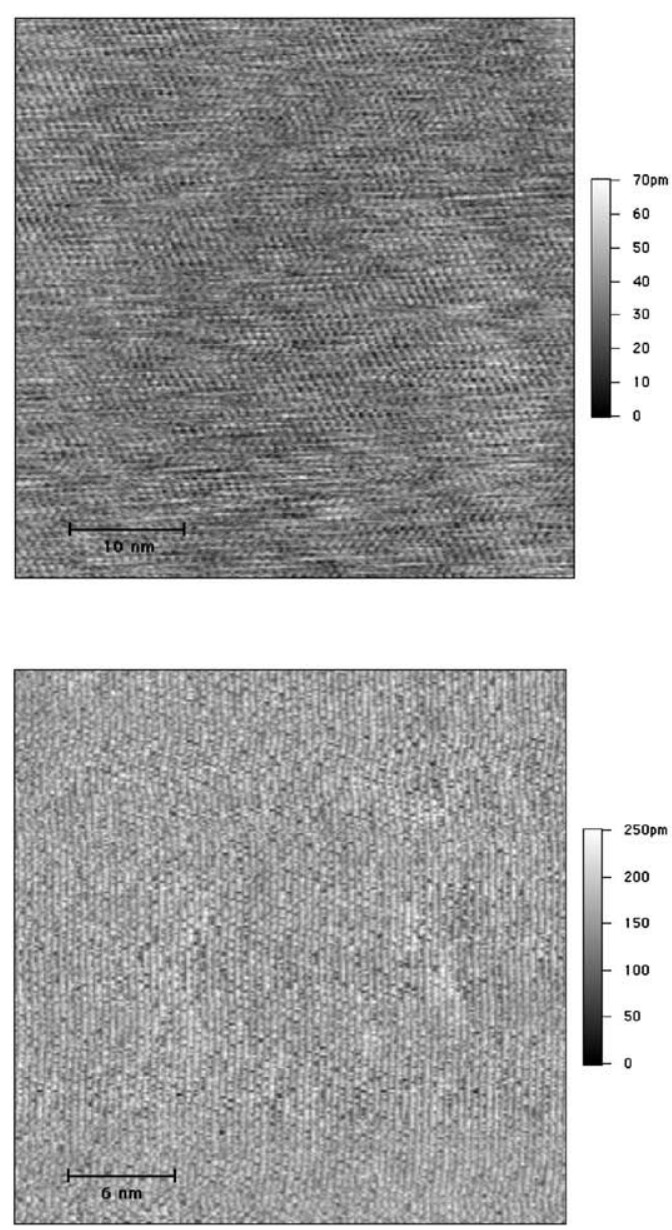
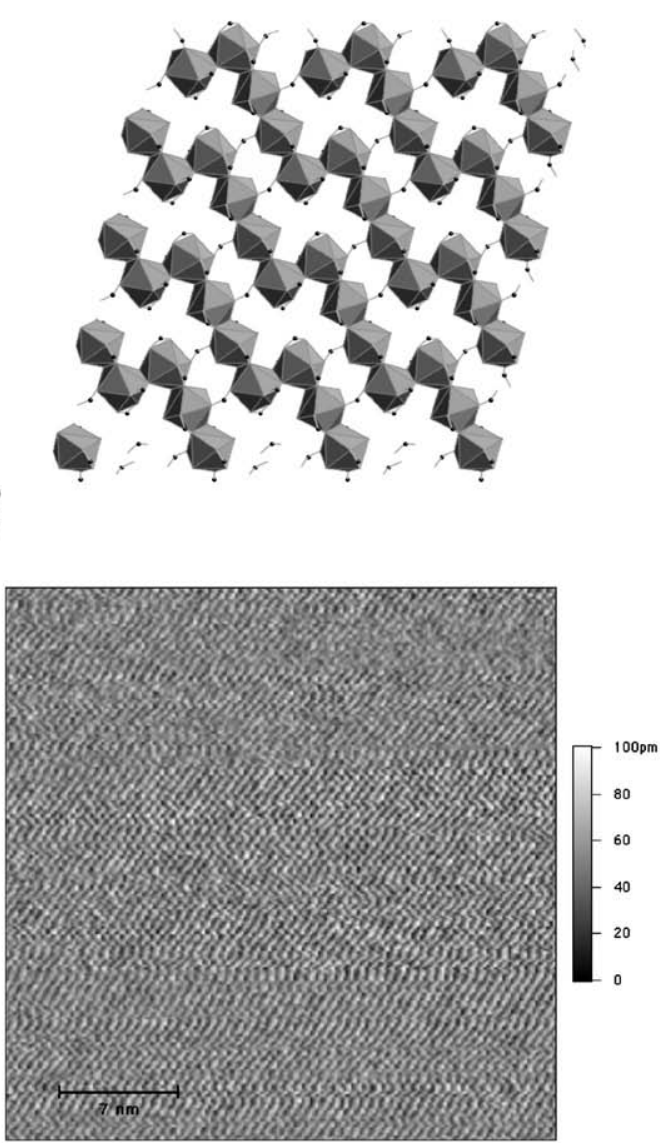

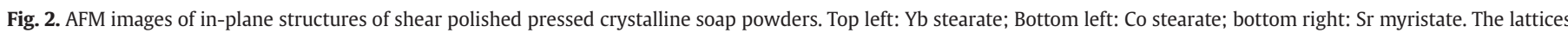
structures and sizes are in agreement with XRD and FTIR data [53*] and the model (top right) is created from data and is the crystal structure of La butyrate [63*]. 
melt-re-crystallized myristates, including terbium and thulium myristates. This is a general finding, and as will be discussed later, most likely relates to the loss of coordinated water crystallized in the polar sheets and formation of disordered soaps upon re-crystallization from the melt. However, the thermal and hydration history of any particular lanthanide soap generally does not influence its first order transition temperatures on fusion (to the anisotropic liquid), nor on transitioning from the 2D-1D MOF headgroup network to form a second SmA mesophase ( $\mathrm{SmA2}$ here). But the thermal history is probably implicated in the variation of heat change (actually heat capacity change) and temperature ranges for the second order (or weakly first order) shoulder commonly preceding the main first order transitions on heating and cooling using DSC $\left[42^{*}, 53^{* *}\right]$, and significantly in broadening the stability fields for liquid-crystalline mesophases.

Hydration appears to increase order within the 2D MOF polar layer of soaps, and the hydrocarbon chains to which the polar layer is coupled (as evidenced by the relatively sharper, more intense peaks in both wide-angle XRD and the progression bands in FTIR spectra compared with anhydrous soaps). Hydration does not appear to change the general phase transition sequence or long spacings determined by XRD $\left[42^{*}, 53^{* *}\right.$, rather the large enthalpy of dehydration acts to demarcate subtle changes in the MOF polar groups, because dehydration appears to trigger dehydration. This will be discussed later.

The extra order induced by hydration, the lack of other effects during heating (other than increased total enthalpy change) and the position of water molecules in the lanthanide butyrate crystal structures suggest the water of hydration stabilizes the headgroups by hydrogen bond bridging, without affecting the overall metal-oxygen (carboxyate) topology. Dehydration simply reduces the coordination number of the metal, and lanthanides can easily tolerate a lowering in coordination, particularly the larger ions. Nonetheless, and despite efforts to remove water from the polar layer using vacuum drying and storage over drying agents[53*], or solvent re-crystallization $\left[42^{* *}, 46^{*}\right]$ residual hydration plays a role in the subtle pre-chain melting transitions observed here. Indeed it is known that water can effect the topology and density in MOFs as demonstrated for cobalt succinate up to $190^{\circ} \mathrm{C}\left[60^{\circ}\right]$.

\section{Phase transitions in the lanthanide soaps}

The following discussion is essentially based upon re-analysis of the previously unpublished data of Corkery [53*], with significant

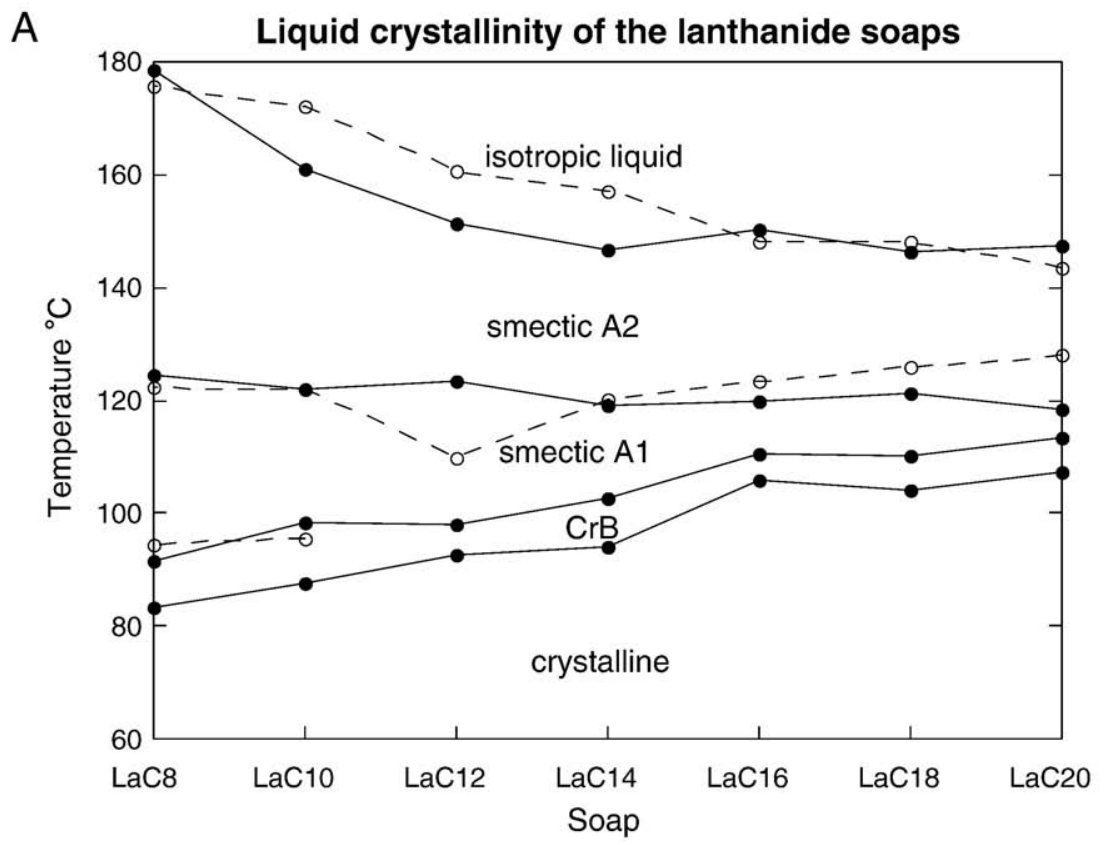

B
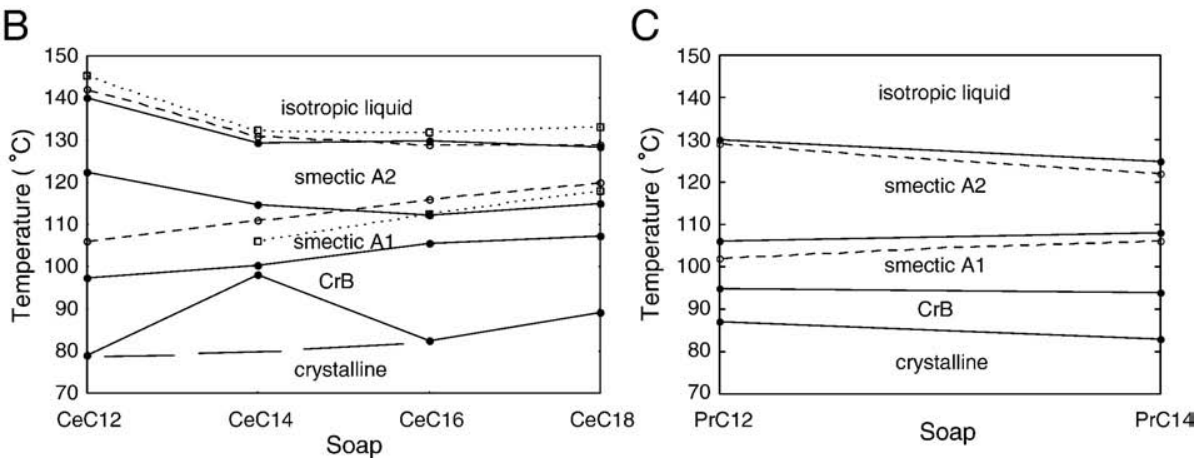

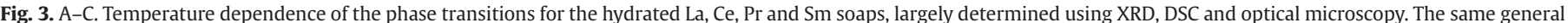

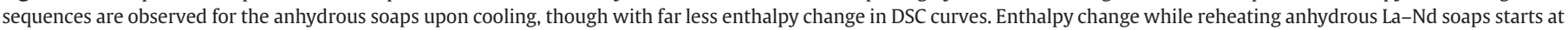

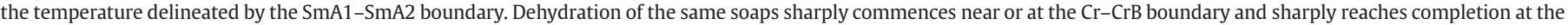

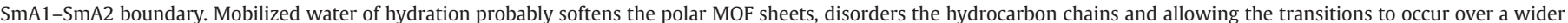

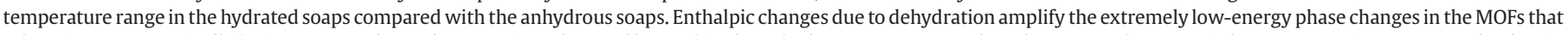

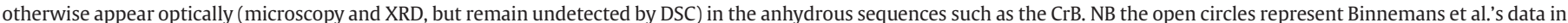

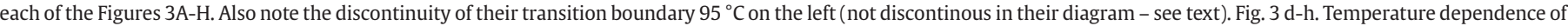

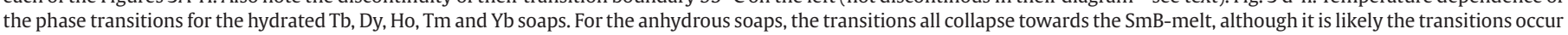
in the same or nearly the same order, but compressed in temperature range - see the text for a discussion. 

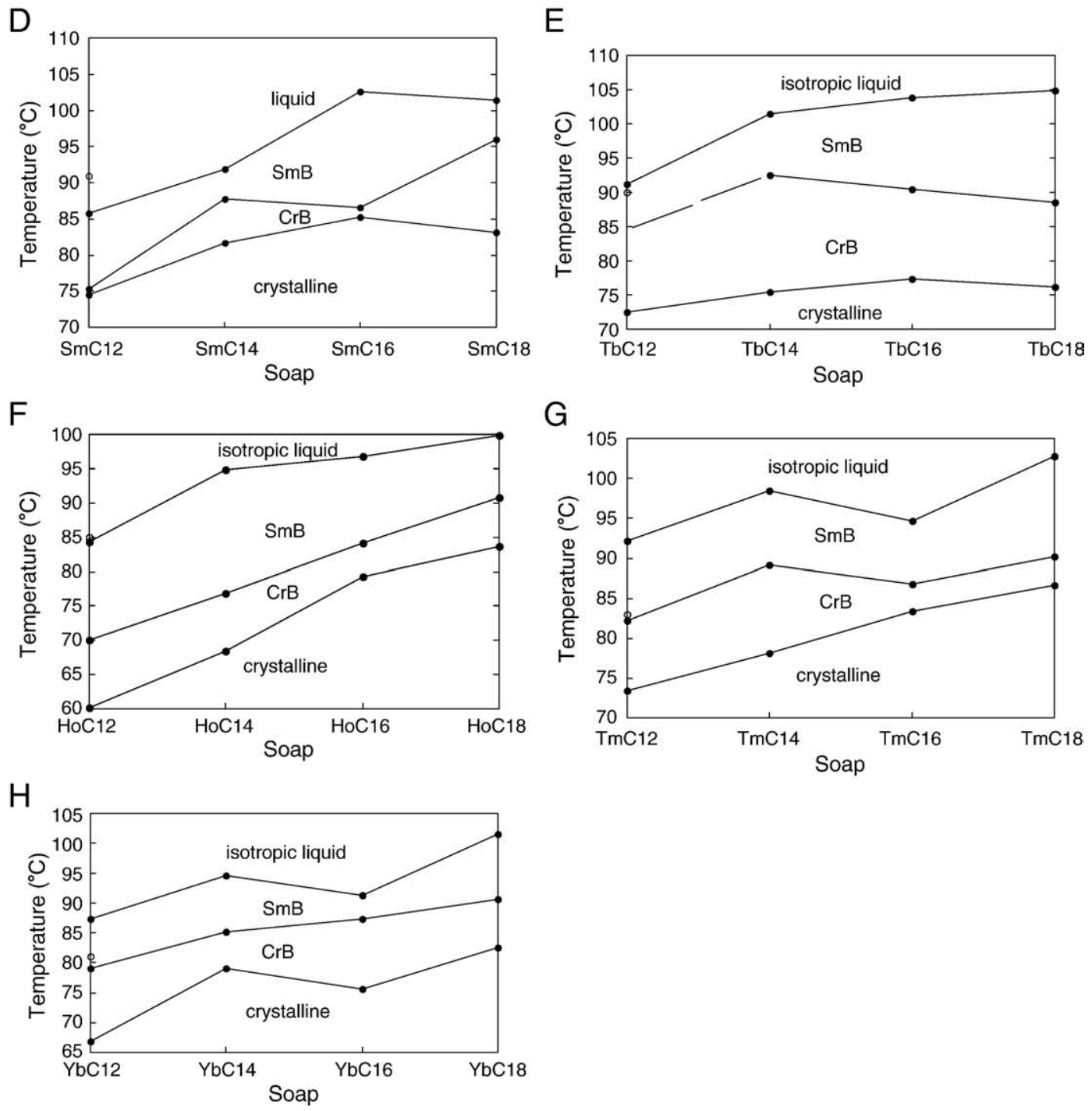

Fig. 3 (continued).

additional interpretation, particularly the effect of hydration and topology changes in metal-oxygen networks, and is meant to complement and extend the works of others discussed in the Introduction, primarily by Binnemans et al. and Marques et al.

The general sequence of thermotropic phase transitions involves expansion of the hydrocarbon chains via increasing rotational disordering of the chains with simultaneous dehydration (for hydrates), conformational disordering of the chains and concomitant expansion, disordering and depolymerization of the polar metaloxygen network. The general sequences argued below for the longchain $\left(>C_{12}\right)$ soaps of the lanthanides are:

La-Nd: crystalline ( $\mathrm{Cr}$ )-crystalline smectic rotor phase $(\mathrm{CrB})-$ partially molten-chain smectic (SmA1)-molten-chain smectic (SmA2)-ordered melt; and

$\mathrm{Sm}$ - $\mathrm{Lu}$ : crystalline $\mathrm{Cr}$ )-crystalline smectic rotor phase (CrB)-conformationally disordered smectic rotor phase (SmB)-ordered melt.

Incorporating transitions in the MOF topology, the general sequences then equivalently become:

La-Nd: (de)hydrated Cr-2D MOF-hydrated-dehydrated CrB-2D MOF-dehydrated SmA1-2D MOF-dehydrated SmA2-1D MOFdehydrated Melt-1D MOF
Sm-Lu: (de)hydrated Cr-2D MOF-hydrated-dehydrated CrB-2D MOF-dehydrated SmB-1D MOF-Melt-1D MOF.

For brevity, the upper naming strategy has been used throughout.

4.1. Crystalline lamellar herringbone to (disordered) crystalline lamellar rotor phase (C1-CrB)

The term 'herringbone' is meant to convey the fact that these soaps have hydrocarbon chains in all-trans conformation, and packed in well-defined crystalline sub-cells [79*], and with additional X-ray spacings in the wide-angle interpreted as crystalline arrangements of the in-plane metal-oxygen 1D and 2D chains and sheets.

The small continuous change in heat capacity during this transition is best attributed to small amounts of conformational disorder (gauche bonds) and orientational disorder (chain rotations) induced by the increased thermal agitation of the previously well-crystallized chains, with the effect amplified by dehydration. This first transition is a second order, continuous change in the state of the chains and hydration - as judged from the slope change in the DSC curve (e.g., Fig. $4, \mathrm{ca} .80-105^{\circ} \mathrm{C}$ ). This second order change has not been observed (optically) in all lanthanide soaps but has been detected using DSC and also with XRD (Fig. 5). Subtle increases in refractive index contrast at the edges of hydrated polycrystalline 
soap aggregates during heating are coincident with the onset temperatures recorded using DSC, and dehydration temperatures using TGA.

For some soaps, it is the corresponding change in the XRD pattern that confirms the higher temperature phase of this transition is related to a smectic B rotor phase $(\mathrm{CrB})$, with non-tilted (or very nearly vertical) chains. A single XRD chain-packing peak for this phase was found at about $4.2 \AA$ for both cerium and praseodymium myristates (illustrated in Fig. $5-90{ }^{\circ} \mathrm{C}$ and Fig. $6-$ $95{ }^{\circ} \mathrm{C}$ ), consistent with the rotor phases found in lyotropic systems (e.g., $\mathrm{L}_{\beta}$ of triglycerides - e.g., Larsson [ $80^{*}$ ]). This 2 nd order phase change also results in the loss of the in-plane headgroup crystallinity of the super-lattice formed by the MOFs, but most likely with no change in the metal-oxygen network topology, nor significant conformational disordering of the chains. In the anhydrous soaps, the same description applies, but generally shifted to higher temperatures.

In the case of lanthanum soaps, the transition from fully crystalline to the completely molten-chain liquid-crystalline state occurred over a just a few degrees passing only briefly through the crystalline rotor phase ( $\mathrm{CrB}$ ). The DSC patterns clearly show this as a significant but small skewing of the chain-melting peak to lower temperatures.

The slight shortening of the crystalline long spacing measured at this transition $(\mathrm{CrB}-\mathrm{SmB})$ in $\mathrm{Ce}(1.6 \pm 0.1 \AA)$ and Pr myristates $(1.0 \pm$ $0.3 \AA$ ) is significantly smaller than the expected shortening (ca. $2.1 \AA$ ) due to the formation of two kinks (G-T-G) per molecular length, and is more consistent with the formation, on average, of a single gauche bond per chain or less, requiring about $1.6 \AA$ shortening of the long-spacing per soap molecule in the splayedchain arrangement [81]. The increase of the chain-packing peak (from $d=4.05 \AA$ to $4.23 \AA$ ) is synonymous with an increased interfacial chain cross-sectional area from about $18.9 \AA^{2}$ to $20.6 \AA^{2}$ per hydrocarbon chain (assuming no defects). The XRD chain-packing peak is well-defined, indicative of long-range positional ordering of the otherwise rotationally disordered hydrocarbon chains, or large crystalline domains. The MOF headgroup (where the chains are anchored) is expected to restrict positional disordering of the hydrocarbon chains, particularly near the polar layer (in contrast to molecular motions of the $n$-paraffins). The XRD-determined average distance between hydrocarbon chains in the crystalline rotor phase $(\mathrm{CrB})$ is ca. $4.9 \AA$, exactly the value accepted for ideal free hydrocarbon-chain rotations [80*].

\subsection{Crystalline rotor phase ( $\mathrm{CrB})$ to partially molten rotor phase ( $\mathrm{CrB}-\mathrm{SmB})$}

Prior to complete chain melting, and after the onset of dehydration, the hydrated soaps of the heavier lanthanides pass through a first order transition into a mesophase tentatively assigned to a smectic rotor phase with partially molten hydrocarbon chains $(\mathrm{SmB})$. The assignment is based on the detection of birefringence

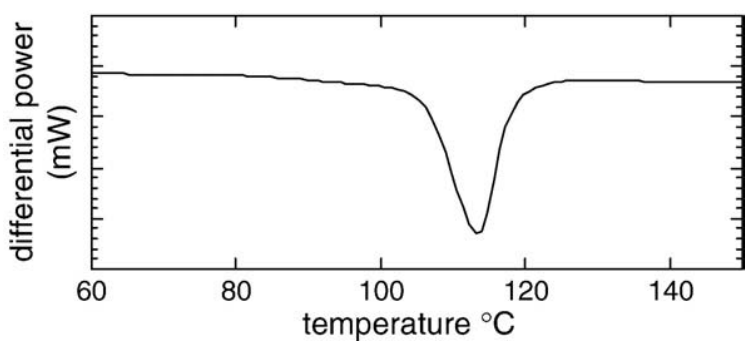

Fig. 4. DSC showing 1st order overlapping CrB-SmA1, SmA1-SmA2 transitions in hydrated cerium palmitate. The SmA2-melt transition was not detected by DSC, but was be easily detected optically, illustrating the low energy of the transition.

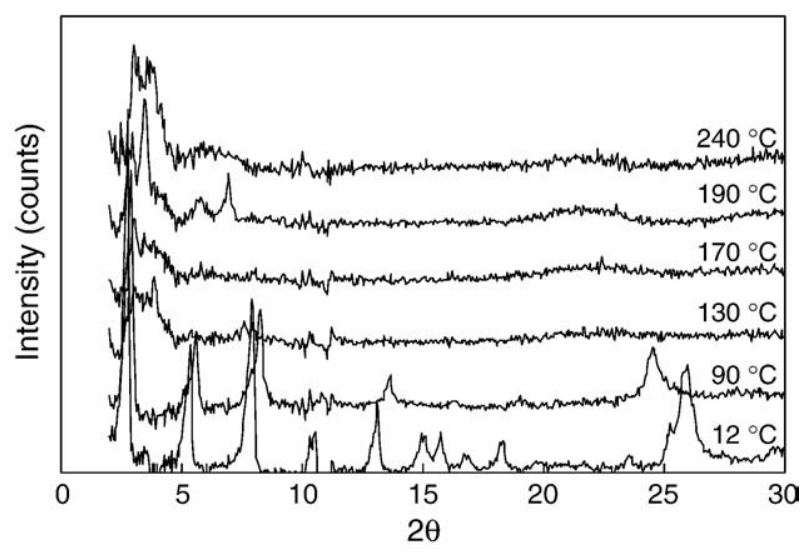

Fig. 5. XRD heating traces for hydrated cerium myristate. $12{ }^{\circ} \mathrm{C}-\mathrm{CrB}(d=39.63 \pm 0.03 \AA)$; $90{ }^{\circ} \mathrm{C}-\mathrm{CrB}(38.8 \pm 0.2 \AA) ; 130{ }^{\circ} \mathrm{C}$-remnant peak of SmA2 $(d=28.4 \pm 0.3 \AA) ; 170{ }^{\circ} \mathrm{C}$ - melt. NB the $\mathrm{CrB}$ phase at $90{ }^{\circ} \mathrm{C}$ is probably substantially dehydrated. The apparent mesophase peaks at $190{ }^{\circ} \mathrm{C}$ and $240^{\circ} \mathrm{C}$ are attributed to those induced by the oxidation of Ce(III)-Ce(IV).

and anisotropic optical textures, trends in expected phase sequences (non-lamellar phases have not been observed amongst the soaps discussed here) and the appearance of split chain-crystallization exotherms in DSC cooling curves. However no positive Xray diffraction has been collected for this phase.

Hot-stage optical microscopy of holmium laurate and other soaps, for example, shows a mesophase can grow from an isotropic fluid formed at the transition. These display small focal conics and other birefringent features when held just above the transition temperature. In the case of ytterbium stearate, the phase formed just above the transition could be smeared (beneath a cover slip) to give a texture similar to the fully developed $S m A 2$ phase of, say, praseodymium myristate. In most cases however, the texture change on transitioning to the $\mathrm{SmB}$ mesophase amounts to small particle fusion, smoothing out of domains of small focal conics and formation of isotropic, curved droplets with irregular boundaries. It is possible that dehydration and subsequent re-crystallization to a more thermally stable anhydrous or lower soap hydrate explains the observations in the holmium laurate case, however the re-crystallization temperature for soaps is generally far lower than their melting temperature, thus we favor an assignment to a partially molten rotor phase that is dehydrated. Importantly, dehydration can continue through this phase region, depending upon the dehydration rate, and thus it is can be considered a two

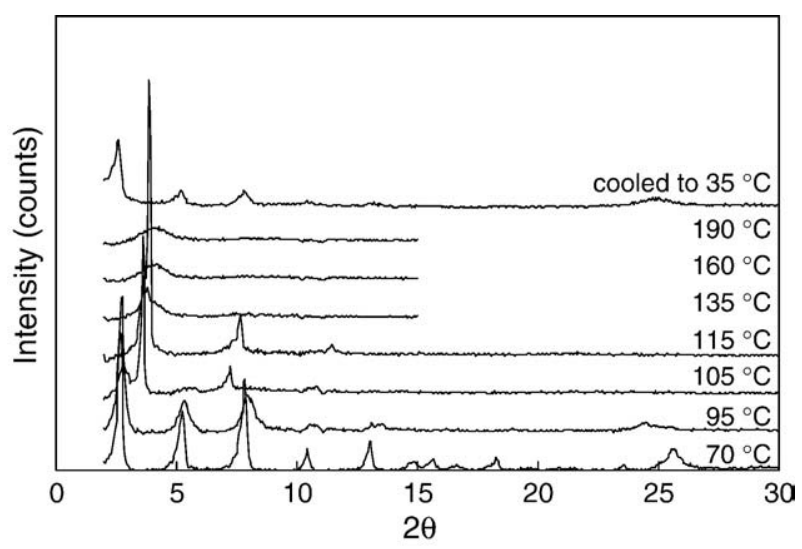

Fig. 6. XRD heating traces of praseodymium myristate $-\mathrm{Cr} 70{ }^{\circ} \mathrm{C}(39.5 \pm 0.2 \AA) ; \mathrm{CrB} 95^{\circ} \mathrm{C}$ $(38.8 \pm 0.2 \AA) ; \operatorname{SmA} 1105^{\circ} \mathrm{C}(28.0 \pm 0.2 \AA) ; \operatorname{SmA} 2115^{\circ} \mathrm{C}(d=27.0 \pm 0.3 \AA) ;$ and melt $>115^{\circ} \mathrm{C}$. Pr laurate: SmA2: $24.5 \pm 0.2 \AA$, ca. $120^{\circ} \mathrm{C}$ (not shown). 
phase region of dehydrating $\mathrm{CrB}+\mathrm{SmB}$ (not counting the expelled water).

In the DSC traces corresponding to soaps of the heavier lanthanides, two main endotherms have been clearly separated in temperature (Figs. 7 and 8) and in some cases an assessment of their separate transition entropies has been possible. Most of the enthalpy change in the first peak is probably due to dehydration of the MOF headgroups. $\mathrm{Yb}$ stearate shows the largest separation of these endothermic events amongst the lanthanide soaps here. A ratio of 1.1:1 for the lower to higher transition entropies respectively. In the even soaps: Ho laurate, Ho myristate, Ho palmitate, Ho stearate, the respective ratios of $\Delta S$ for these endothermic peaks are $1.37: 1 ; 0.59: 1$; $0.23: 1$; and $0.25: 1$.

Lanthanum, cerium, and praseodymium soaps generally show a single or slightly distorted main DSC peak, whereas soaps of $\mathrm{Tb}-\mathrm{Yb}$ display a clear and more equitable distribution of endothermic peaks. This behavior is evidence in favor of a model where the soaps of the lighter lanthanides undergo MOF disordering and topological transitions in a narrow temperature range because they can restrict or dampen conformational disordering of the hydrocarbon chains until higher temperatures are reached, and once they do melt, they do so almost completely because of the higher relative temperature. This may be owed to their more cohesive, thermally stable and more crosslinked 2D MOF headgroups compared with soaps of the heavier lanthanides.

Despite the fact that a significant fraction of the enthalpy change is due to dehydration continuing through the $\mathrm{CrB}$ and $\mathrm{SmB}$ phase regions on heating, significant splitting of DSC peaks was also observed on cooling, though with far less heat change. A possible explanation for the more obvious splitting of the chain re-crystallization transitions involves partial chain melting though the disordering of the chain ends, and/or possible extra mobility of the chains in one direction, e.g., through formation of asymmetric 2D MOFs within the headgroup layer, with freedom for anisotropic hydrocarbon-chain motions. The former state (chain-end disordering) is the probable situation in triple chain triglyceride molecules in their $\alpha$-crystalline state (a crystalline rotor phase like the thermotropic crystalline smectic B) [80]. In either case, if the timing of the recrystallization of the hydrocarbon chains and MOF polar layer during cooling is not coincident, then subtle stepwise re-crystallization of the chains could be expected. There appears to be a subtle balance of MOF structuring and chain packing that can sometimes give split peaks and sometimes not.

\subsection{Crystalline rotor phase to liquid-crystalline smectic phase (CrB-SmA1) (La-Nd)}

The transition to the molten-chain state is confirmed by the onset of a very broad chain-packing peak near 4.5-4.6 $\AA$ in X-ray diffractograms for cerium and praseodymium myristate and praseo-

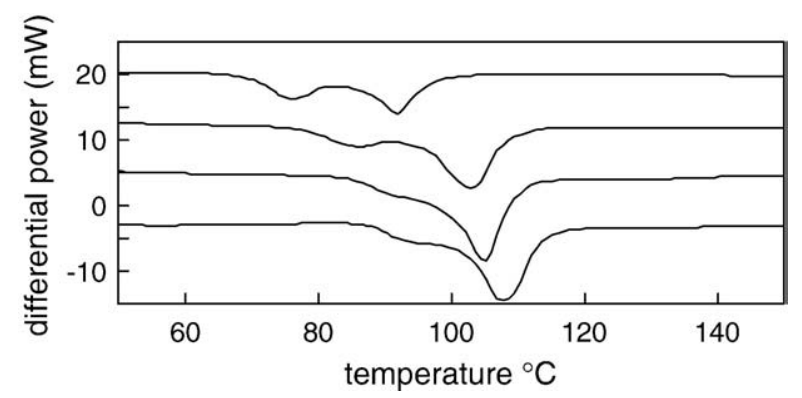

Fig. 7. DSC heating traces of holmium soaps - top to bottom are laurate, myristate, palmitate and stearate. The general transition sequence on heating is $\mathrm{Cr}-\mathrm{CrB}-\mathrm{SmB}-$ melt. The two most enthalpic are the $\mathrm{CrB}-\mathrm{SmB}$ and $\mathrm{SmB}$-melt transitions.

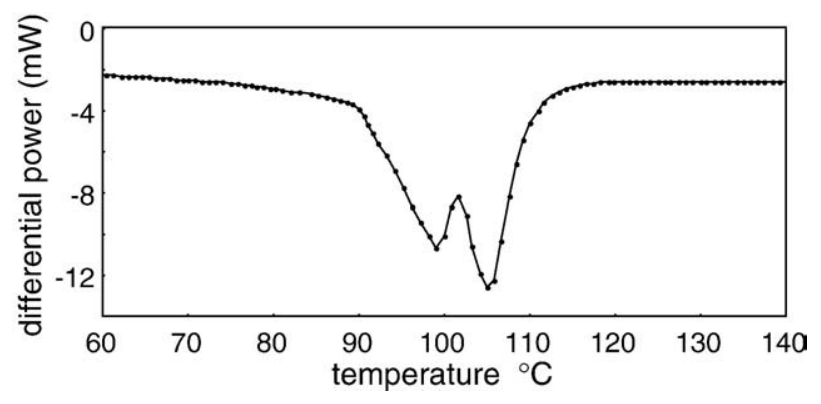

Fig. 8. DSC heating trace of $\mathrm{Yb}$ stearate showing the $\mathrm{Cr}-\mathrm{CrB}$ and $\mathrm{CrB}-\mathrm{SmB}$ and $\mathrm{SmB}-$ melt transitions. The large, low-temperature endothermic peak is predominantly due to dehydration, but as a result of being triggered by rearrangements in the MOF headgroup.

dymium laurate. This is a typical spacing for metal soaps with molten chains [17]. The loss of sharp order in the chain-packing peak and its shift to a significantly higher $d$-spacing at this transition indicates that the metal-oxygen headgroup networks also transition to a somewhat more disordered state compared with their arrangement in the crystalline phase at lower temperature. The change in the position of the chain-packing peak is consistent with an increase in the volume of the chains, as would be expected as the number of gauche bonds increases. The change represents a ca. $30 \%$ increase in the chain crosssection area relative to the room temperature crystalline phase, and an average inter-chain distance of 5.3-5.4 A. The latter value is larger than that needed for free rotation of all-trans chains (ca. $4.9 \AA$ ), the former consistent with the view that the area required for moltenchain liquid-crystalline phases is about $24-25 \AA^{2}$ per hydrocarbon chain if the packing is pseudo-hexagonal [82"]. For comparison, the area per chain in crystalline lanthanide soaps is about 18.9-19.3 $\AA^{2}$. This is similar to typical values found for well-crystallized membrane lipids i.e., 18.2-19.7 $\AA^{2}\left[82^{\circ}\right]$.

The clearly defined DSC chain-melting peak correlates with a slow change observed in the optical microscope for the soaps of lighter lanthanides. For example, in La, Ce and Pr myristates and Pr laurate, the soaps clearly became fully molten-chain smectic phases over the span of $5-10{ }^{\circ} \mathrm{C}$ during heating under the microscope. It is interesting to note that in the lanthanum soaps, the first major optical transition is usually the change from one smectic phase to another. Unusually, the chain-melting transition recorded by DSC is optically invisible under normal circumstances. However, the CrB-SmA1 transition can be detected optically by heating very slowly just below the temperature expected from DSC. At each new temperature step, the cover slip is rubbed until a distinct transition in the viscosity can be detected, and by observing a concomittant change in the smear texture (enhanced using crossed-polarizers with a gypsum plate). Above the DSC melting transition, the soap is easily smeared into large coherent domains, whereas below the transition the soap resists smearing.

The long spacings of the molten chain lamellar (SmA1) phases seen above the chain-melting temperature are illustrated in Fig. 6 (105 and $\left.115^{\circ} \mathrm{C}\right)$ and Fig. $9\left(120^{\circ} \mathrm{C}\right)$ and are discussed in the next section.

This transition from the $\mathrm{CrB}-\mathrm{SmA} 1$ mesophase represents a significant change in both the chain conformational order and the density of the metal-oxygen headgroup network. The hydrocarbon chain-length dependence of the transition temperature, and the relatively high viscosity of the SmA1 phase (compared to the SmA2) suggests that the organization in the metal-oxygen network at this transition remains relatively cohesive. This is despite the increased mean area-per-metal due to chain melting driving the metals apart (see analysis section below). This implies that during the transition, the larger La, Ce and Pr ions can remain bonded with the same or similar topology as their former 2D or fairly tightly packed 1D networks, unlike soaps of the smaller, heavier lanthanides. Essentially 


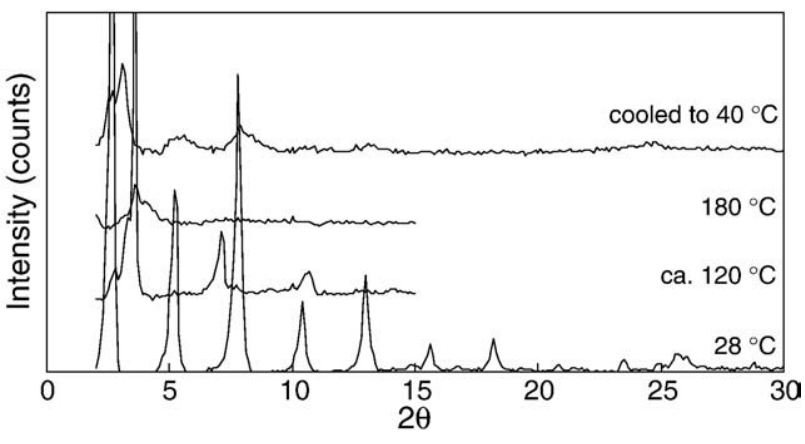

Fig. 9. XRD heating traces of La myristate showing the room temperature phase at $28{ }^{\circ} \mathrm{C}$ $(d=39.73 \pm 0.07 \AA)$ (and a remnant at $120^{\circ} \mathrm{C}$ ). At $120^{\circ} \mathrm{C}$, the higher temperature smectic phase $(\mathrm{SmA2}, d=29.0 \pm 0.2 \AA)$ shows Bragg peaks to the third order. A minor shoulder on the primary long-spacing peak of the second smectic phase $\left(120^{\circ} \mathrm{C}\right)$ is assigned to the first smectic phase (SmA1, $d=31.4 \pm 0.3 \AA$ ).

this transition can be viewed as a chain-melting event, where any change in the metal-oxygen network topology has minimal impact on both its cohesivity and 2-dimensional connectedness, though it must expand from a more compact to an open structure to accommodate the more voluminous hydrocarbon chains (Figs. 10 and 11).
The SmA1 mesophase has not been previously reported for longerchain lanthanide soaps. Binnemans et al. have noted an unidentified smectic "M" mesophase, and indicated its phase stability region as ending abruptly [43-45,47*]. Marques et al. [42*] also noted this phase in cerium laurate. The lack of reports on this mesophase is probably because of the coincidence of the $\mathrm{CrB}-\mathrm{SmA} 1$ endotherm with the higher SmA1-SmA2 endotherm, and the lack of optical indicators due to the rigidity and cohesiveness of the mesophase that is likely cross-linked by a 2D-connected MOF, particularly for more viscous longer-chain length soaps. However, if we project the phase boundaries of Binnemans et al.'s abruptly ending M-SmA transition temperatures, we predict the existence of their ' $M$ ' mesophase exactly where we find the current 'SmA1' mesophase. Therefore it is likely their ' $\mathrm{M}$ ' mesophase and the current 'SmA1' mesophase are identical. Similarly their SmA phase is equivalent to the current SmA2 mesophase.

\subsection{Smectic A to Smectic A' transition (SmA1-SmA2)}

Above the transition temperature for molten chains, and coincident with the termination of dehydration, the X-ray diffraction patterns of the La, Ce and Pr soaps indicate further polymorphism as illustrated in Figs. 6 and 9.

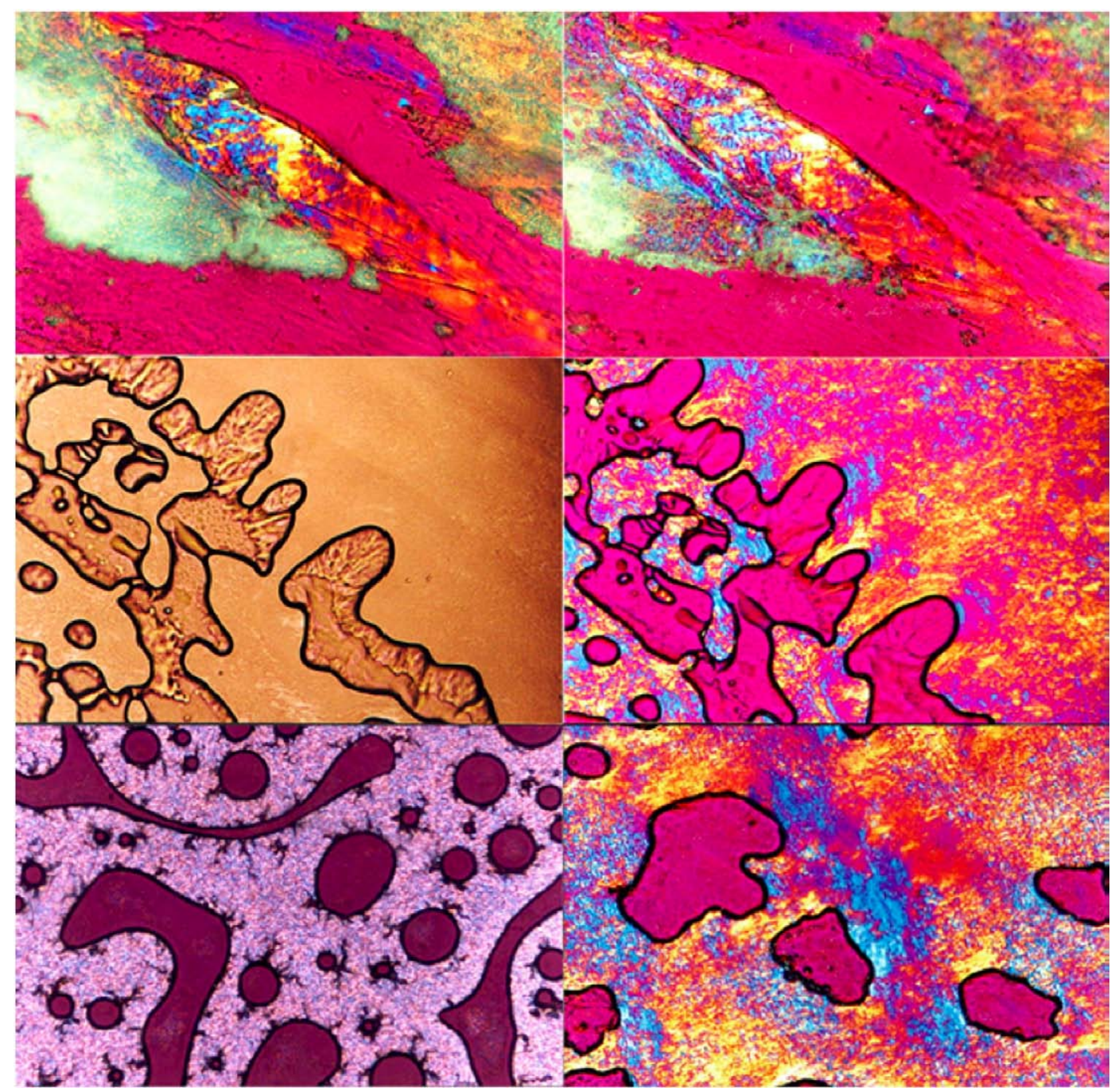

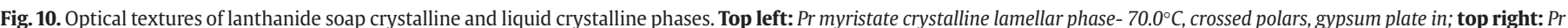

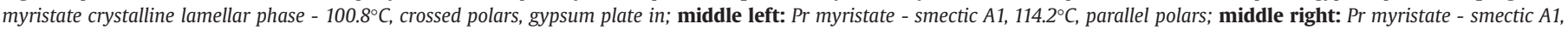

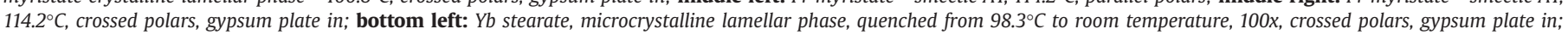
bottom right: $Y b$ stearate, molten rotor phase $(\mathrm{SmB})$, held at $94.4^{\circ} \mathrm{C}$ for two minutes, $200 \mathrm{x}$, crossed polars, gypsum plate in. 


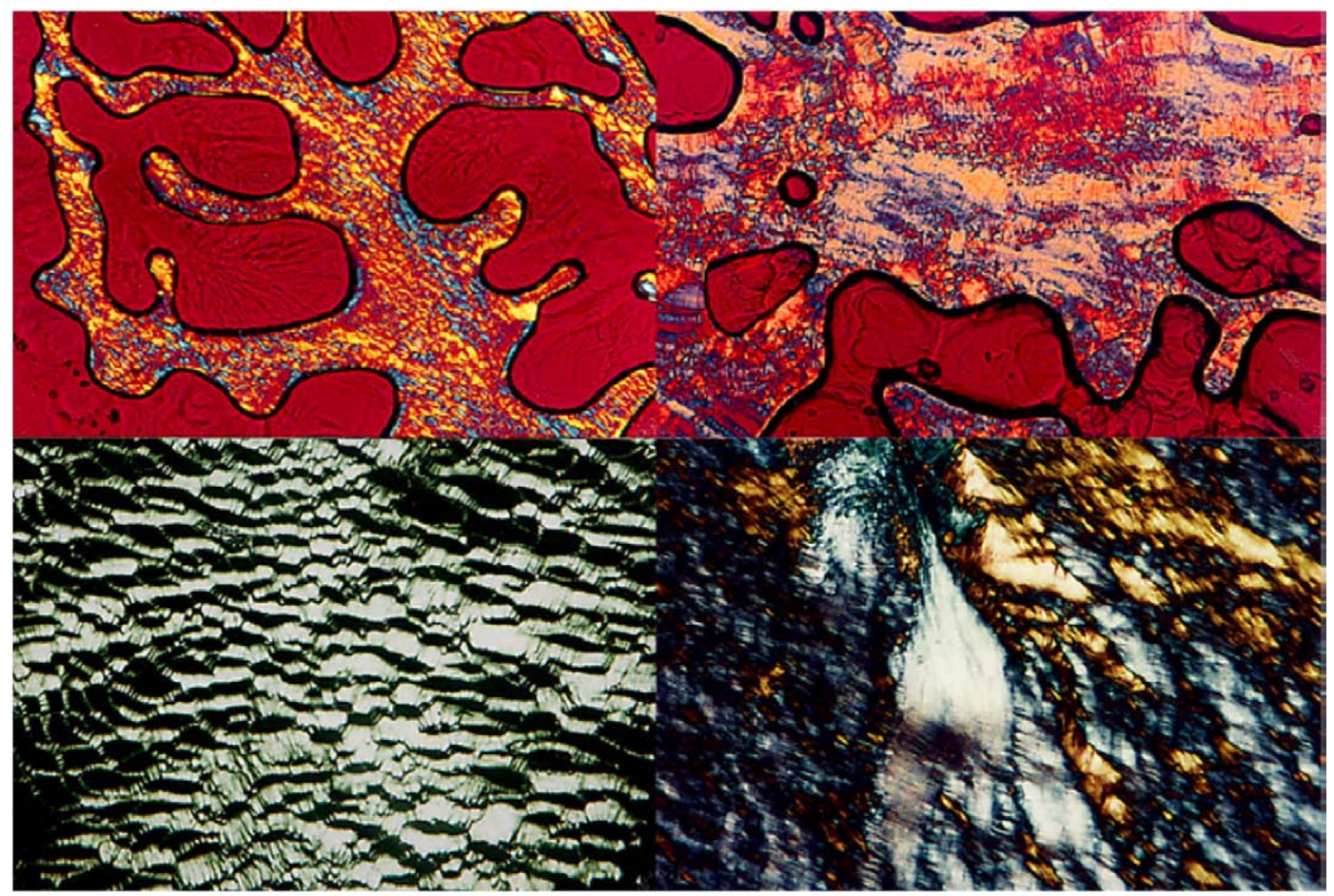

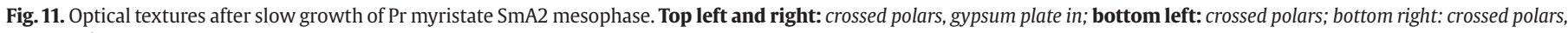
gypsum plate in.

The X-ray diffractogram of praseodymium myristate at $115{ }^{\circ} \mathrm{C}$ (Fig. 6) shows the coexisting disappearance of the first SmA1 phase and the onset of the new SmA2 phase. This is also seen in the trace of lanthanum myristate at $120{ }^{\circ} \mathrm{C}$ (Fig. 9) (The coexistence of these phases (and the original crystalline lamellar phase) is likely due to the short thermal equilibration time between XRD runs (120 s), and the low thermal conductivity of the samples and pyrophyllite sample holder).

This transition from SmA1-SmA2 is easily detected using optical microscopy and is characterised by the onset of fluid motion and the appearance of streaky, strongly birefringent domains. This transition is rarely detected using DSC carried out at the same heating rate as was used for optical microscopy $\left(10{ }^{\circ} \mathrm{C} \mathrm{min}^{-1}\right)$. Indeed, if the transition is due to metal-oxygen rearrangement, the amount of heat expected to be absorbed at this transition would be small (Table 1).

The chain-length dependence of the SmA1-SmA2 transition temperatures is very weak (centred around $120{ }^{\circ} \mathrm{C}$ for lanthanum soaps - Fig. 2), lending more support to the idea that this transition is due to a significant (though low energy) rearrangement in the metaloxygen network. Note that such a rearrangement must involve an increase in the average molecular interfacial area to account for the increased average chain cross-sectional areas. Therefore, the change likely includes a change in the site symmetries and coordination number of the lanthanide ions and also a change in the carboxylate binding (both of these changes should be easily detected spectroscopically at the appropriate temperatures, but were not measured in this study).

The transition probably involves a disordering of the 2-D metalcarboxylate coordination polymer headgroup layers, where the disorder is confined to the layers. The observation of easy smearing to large domains supports a model where the 2D metal-oxygen network of the SmA1 breaks down into weakly interacting 1-D ionic coordination polymers in the $S m A 2$ mesophase, with average in-plane separation of the metal-oxygen polymer chains similar to the interchain distance of approximately $5.3 \AA$. The possibility that this phase maybe stabilized by transient weak interactions of $1 \mathrm{D}$ coordination polymers to give labile 2D networks is considered likely, particularly for the La and Ce, but less so for the smaller Nd soaps. The difference in viscosity noted by Binnemans et al. [46*"] for the respective SmA1 phases of La and $\mathrm{Nd}$, taken together with the analysis represented in Fig. 13, suggests that the difference may arise from the relative degree of 2D cross-links in each phase at any given moment, i.e., La soap more polymerised than the Nd soap.

\subsection{Liquid crystalline to melt phase transitions}

The long-chain, saturated soaps of heavier lanthanide ions (Sm$\mathrm{Yb}$ ) do not display a SmA1 or SmA2 phase beyond their respective chain-melting temperatures. Rather, they transit directly to the melt. At the melting point, the relatively large hydrocarbon chain area at the polar interface cannot be matched by an expansion of the metaloxygen coordination networks in soaps of heavier lanthanides, because their $\mathrm{M}-\mathrm{O}$ bond lengths are relatively shorter.

The 'melt' phase of the lanthanide soaps here is an optically isotropic, free flowing liquid that displays a strong low-angle X-ray diffraction maxima indicating the presence of very short-range anisotropic structures. A single low-angle X-ray intensity maxima observed in the xrd patterns soaps and in triglyceride melts and interpreted to arise from either small paramellar units or short, 1D labile rod units assembled into very small ordered domains similar (but much smaller) to those in nematics or columnar phases $\left[26^{*}, 34,42^{*}, 52^{\bullet}, 80^{*}, 83^{\bullet}, 84-87\right]$. Shear birefringence seen in branched fatty acid soaps of Lu, probable rod mesophase formation in the

Table 1

X-ray long spacings for SmA1 and SmA2 mesophases

\begin{tabular}{llcl}
\hline Soap & Smectic phase & d-spacing $\AA$ & Temperature ${ }^{\circ} \mathrm{C}$ \\
\hline La myristate & SmA1 & $31.4 \pm 0.3$ & ca. 120 \\
La myristate & SmA2 & $29.0 \pm 0.2$ & ca. 120 \\
Ce myristate & SmA2 & $28.4 \pm 0.3$ & 130 \\
Pr myristate & SmA1 & $28.0 \pm 0.2$ & 105 \\
Pr myristate & SmA2 & $27.0 \pm 0.3$ & $117-120$ \\
Pr laurate & SmA2 & $24.5 \pm 0.2$ & ca. 120 \\
\hline
\end{tabular}


branched soaps of La and Ce and arguments based on surfactant packing parameter favor very short-range non-lamellar ordering. The spacings of the molten lanthanide soaps of saturated fatty acids appear to fall into three distinct sets, i.e., (La,Ce,Pr); (Sm,Eu); and (Tb, $\mathrm{Dy}, \mathrm{Ho}, \mathrm{Tm}, \mathrm{Yb}$ ). The particular division of the lanthanide soaps above mirrors the division based on their room temperature, in-plane metal-oxygen super-structures and FTIR spectra [53**] and dehydration enthalpies [46"*]. It is therefore likely that 1D coordination polymers comprise the melt, though significantly less polymerised (shorter) than in the SmA2 mesophase, given the much lower relative viscosity, and the increased hydrocarbon-chain volumes.

\subsection{Cooling behaviour}

The cooling behaviour for many lanthanide soaps duplicates (in reverse) the main features observed in the DSC traces for the particular soaps upon heating. The important features on cooling these soaps are the ubiquitous shift of the transitions to lower temperatures and the general reduction in the magnitude of the respective transition enthalpies due to crystallization of disordered phases $\left[422^{*}, 43,53^{* *}\right]$. Further the splitting of exothermic cooling peaks into discrete chainre-crystallization events is observed for some soaps (Fig. 12A,B).

A shift of about $10-30{ }^{\circ} \mathrm{C}$ is generally recorded for the difference between heating and cooling transitions for most soaps, the cooling transition commonly very sharp, with several consecutive exothermic peaks corresponding to the same heating transitions. Sometimes the twin chain-re-crystallization peaks do not share the chain ordering enthalpy change in the same ratio they did when heated. The lanthanum soaps retain their main single transition, whereas in cerium soaps, the transitions split into two distinct chain re-crystallization events (SmA2-SmA1-CrB). In samarium and thulium stearates, the chain re-crystallization transitions are split into three significant exotherms, most likely due to a more complex interplay of MOF network formation and hydrocarbon-chain ordering.

Some lanthanum, cerium and praseodymium soaps show a small exothermic, first order transition from the melt to the their respective SmA2 phases prior to the onset of chain re-crystallization - associated with the reorganization of hydrocarbon chains into a lamellar phase. But often the transition remained undetectable by DSC, due to the low energy of MOF rearrangements being swamped by the hydrocarbon chain re-crystallization event. This transition is generally easily detected by optical microscopy about $10-20{ }^{\circ} \mathrm{C}$ lower than the respective transition temperature on heating. The transition is generally followed by a subtle but distinct loss of sharpness in the liquid-crystalline textures, and growth of a finer lamellar texture showing smectic patterns like focal conics and Grandjean terraces stable to room temperature.

Lanthanide soaps showing wide separation of their respective main transition peaks on heating can be cooled from the molten-chain state into their respective super-structured crystalline lamellar phases without further transitions, just a few degrees below their respective melting transition temperatures (Recall the that super-structured crystalline lamellar phase has wide-angle peaks arising from ordered 2D metal-oxygen networks). For example thulium laurate, holmium stearate, ytterbium stearate, terbium stearate all show these features. In the case of ytterbium stearate, the partially molten rotor phase (intermediate to the crystalline and molten-chain phases) is detected optically during cooling at a few degrees below its initial melting point, correlating with the wide separation of the two chain-melting transitions. It was characterised by spherulite growth in roughly hexagonal domains, and when cooled from this temperature gave an XRD pattern corresponding to a phase with well-developed 2D MOF super-structure.

However if the chain-melting transitions are close together for a particular soap, that soap will generally form small spherulites surrounded in isotropically oriented lamellar microcrystallites upon cooling, indicative of growth of flexible lamellae. This suggests that the re-crystallization of soaps with weak and narrow, or no chainmelting separation show a chain-re-crystallization transition prior to re-crystallization of the MOF headgroup, and thus crystallize on the whole with relatively disordered metal-oxygen super-structures, though with mainly crystalline chains in all-trans conformation.

\section{Comments on the dehydration of MOF polar layers}

Overall the main effect of hydration is to broaden the temperature span over which lanthanide soaps transition from crystal to liquid, and to act as an effective reporter or demarcator of subtle, low-energy rearrangements of the MOF headgroups, since it is these rearrangements of the MOF that likely trigger the relatively high-energy dehydration in the first place.

The tight temperature regime over which water is lost during TGA $\left(20{ }^{\circ} \mathrm{C} \mathrm{min}-1\right.$, flowing air) in the soaps of the lighter lanthanides stands in contrast to the wider range for the soaps of the heavier lanthanides. For La myristate monohydrate, the dehydration occurs linearly over a range of $94-119^{\circ} \mathrm{C}$, exactly the range of the $\mathrm{CrB}$ and $\mathrm{SmA} 1$ phases. The same is the case for $\operatorname{Pr}$ myristate monohydrate: $90-116{ }^{\circ} \mathrm{C}$. The dehydration enthalpy for Pr myristate is $c a .60 \mathrm{~kJ} \mathrm{~mol}^{-1}$ or $50-60 \%$ of the total heat adsorbed going from the crystal to the liquid state. For Ho palmitate monohydrate, the loss starts at the $\mathrm{Cr}-\mathrm{CrB}$ transition temperature, at $85{ }^{\circ} \mathrm{C}$, but continues at a linear loss rate until $142{ }^{\circ} \mathrm{C}$, and an estimated dehydration enthalpy of $c a .40 \mathrm{~kJ} \mathrm{~mol}^{-1}$.

These dehydration enthalpies are in the range found for the difference in reported $\Delta \mathrm{H}$ for hydrated versus dehydrated lanthanide laurates $\left(30-90 \mathrm{~kJ} \mathrm{~mol}^{-1}\right.$ ) [46"*]. The enthalpy of dehydration for lanthanide laurates hydrates increases smoothly with increasing atomic number for soaps of the heavier lanthanides (see Supplementary information Fig. S3), consistent with a common mechanism of dehydration (assuming equal waters of hydration). The trend is not so for the soaps displaying the SmA1 and SmA2 mesophases, but the enthalpies are close to the same values. The dehydration behavior for Eu-Lu laurates fits both the trends and values obtained by Masuda [88], where they observe an increase in enthalpy from $109-147 \mathrm{~kJ} \mathrm{~mol}^{-1}$ for the dehydration of analogous lanthanide formates across the period
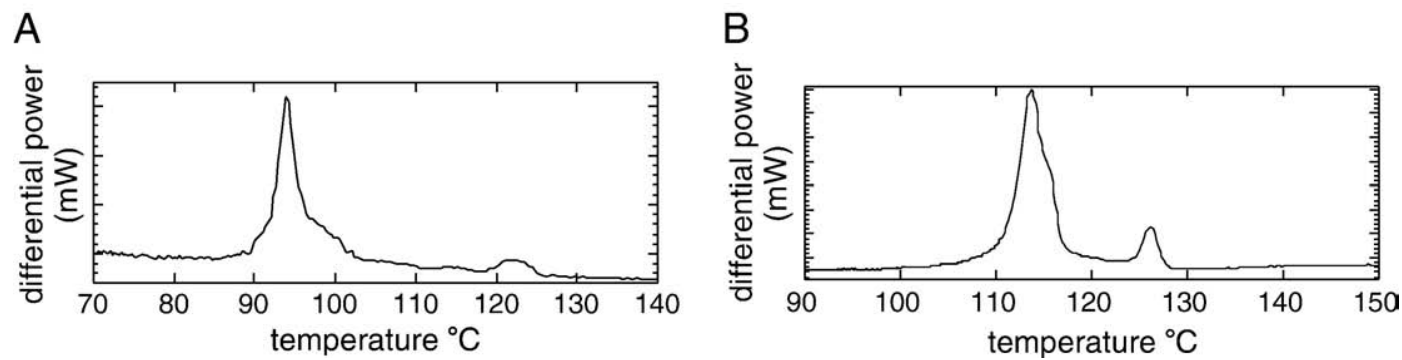

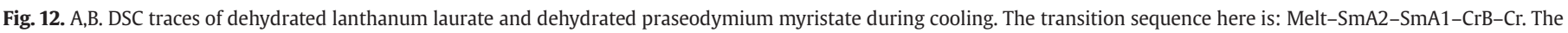

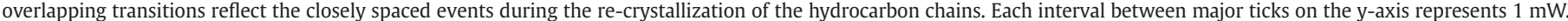


(corresponds to $55-75 \mathrm{~kJ} \mathrm{~mol}^{-1}$ for the monohydrates, and $27-38 \mathrm{~kJ} \mathrm{~mol}^{-1}$ for the hemi-hydrates ( 0.5 waters). The trend correlates with increased electronegativity across the period. Significantly for this study, Masuda also indicated that the rate of lanthanide formate dehydration was controlled by a chemical process at a phase boundary, as is also indicated here by the coincidence of dehydration and phase boundaries. By analogy, and taking into account the TGA results here, the difference in total $\Delta H$ (from crystal-liquid) for hydrated versus anhydrous metal soaps is owed mostly to the enthalpy of dehydration, (a function of the electronegativity of the ion) and is controlled by changes in MOF headgroup structure.

Because dehydration is coeval with subtle rearrangements in the MOFs, the relatively large endotherms effectively report the more subtle rearrangements of the MOFs that otherwise occur with small $\Delta \mathrm{H}$ in the anhydrous soaps. For example the proposed loss of $2 \mathrm{D}$ crystalline order in the MOF network that occurs during the 2 nd order $\mathrm{Cr}-\mathrm{CrB}$ transition would otherwise be almost undetectable using DSC. Likewise the transitions from 2D MOF sheets in the $\mathrm{Cr}$ and $\mathrm{CrB}$ mesophases to sheets of 2D MOFs in the SmB and SmA1 mesophases are demarcated with significantly more heat adsorption than would have occurred in the anhydrous phases at the same transition due to some conformational disordering of their respective hydrocarbon chains.

The onset of the crystalline to liquid phase progression of the hydrated mesophases occurs at lower temperatures than in the anhydrous soaps. This requires relatively lower temperature rotational and conformational disordering of the chains. Water in the MOF lattice would increase the average coordination number of the metals, and the likely consequence is longer average $\mathrm{M}-\mathrm{O}$ bond lengths relative to metals with lower coordination number (as in the anhydrous phases). The MOF polar layer is then more flexible (due to lessened electrostatic repulsions in the MOF headgroup) and subject to larger thermal fluctuations. Furthermore, the increased average area-permetal demands the chains be slightly further apart, thus favouring relatively low-temperature transitions to conformationally disordered states.

It is likely that waters of dehydration will initially be trapped in the polar layers, until exit paths open up, e.g., by transient or permanent depolymerization of the 2D MOF network. The cost of opening these paths may very well be the activation energy for dehydration. Dehydration temperatures for lanthanide formates [88] increase across the period, and so for holmium palmitate we can speculate that even though diffusion pathways are open in the melt, the dehydration rate is slow enough that it is not completed prior to passing to the liquid state (recall it becomes fully dehydrated at $142{ }^{\circ} \mathrm{C}$ in TGA run at $20^{\circ} \mathrm{C} \mathrm{min}^{-1}$ ). On the other hand, the weaker hydration of the soaps of lighter lanthanide allows the 2D-1D MOF transition to dictate the termination of dehydration. In any case, the resultant mobile water molecules could further enhance local disordering and rearrangements in the MOF layer that transfers to the chains, inducing further melting.

\section{A brief analysis of the phase transitions in lanthanide soaps}

For a given soap, the average cross-sectional area per chain at the interface increases with heating and can be estimated from the X-ray short-spacings (Table 2).

Due to stoichiometric constraint (three fatty acid chains per metal), we can then obtain the average area per metal $\left(A_{\mathrm{m}}\right)$ at the interface by multiplying the area per chain by 1.5 . As the metal ions become more separated with increasing hydrocarbon-chain area, their propensity to transition from a 2D network to a 1D network must increase. Therefore it is worth testing if the area-per-metal correlates with the observed difference between the soaps of the heavier and lighter lanthanides.

A 2D MOF can be seen as a set of cross-linked 1D MOFs, with adjacent chains separated by a distance, $d_{\mathrm{ac}}$. If $d_{\mathrm{ac}}$ stretches beyond the maximum possible for bonding $\left(d_{\max }\right)$, the 2D network will break. A reasonable maximum working distance is the $\mathrm{M}-\mathrm{O}-\mathrm{C}-\mathrm{O}-\mathrm{M}$ distance. In this case a value of $2.22 \AA$ is used for the $0-0$ distance in a bridging carboxylate (taken from the chain-bridging distance in Nd butyrate) [ $\left.47^{* *}\right]$.

So,

$d_{\max }=2(M-0)+2.22$.

Now if we assume that the 1D MOF chains consist of edge-sharing coordination polyhedra (vertex sharing chains are considered unstable for this analysis), the M-M distance along the chain, $d_{\mathrm{mm}}$, can be approximated as:

$d_{\mathrm{mm}}=2\left((M-O)^{2}-(2.15 / 2)^{2}\right)^{1 / 2}$,

where the $\mathrm{O}-\mathrm{O}$ distance on the shared edge is approximated as $2.15 \AA$.

For a given fixed value of $A_{\mathrm{m}}$ we can then obtain a relationship for plotting the chain-chain separation, $d_{\mathrm{ac}}$, as a function of M-O distance, i.e.,

$d_{\mathrm{ac}}=A_{\mathrm{m}} / d_{\mathrm{mm}}$

The six curves in Fig. 13 below show the inter-chain distance $\left(d_{\mathrm{ac}}\right)$ for edge-sharing MOF chains that have areas fixed at their respective transitions values, i.e., the values occurring at lower and upper bounds of the $\mathrm{Cr}, \mathrm{SmB}$ and $\mathrm{SmA1}$ phases. This separation is plotted versus typical values of Ln-O distances for La-Lu carboxylates. The curve rising to the right is the maximum possible inter-chain distance, $d_{\max }$ plotted versus the same Ln-O distances. Below this curve 2D MOFs are possible, since the inter-chain distance $\left(d_{\mathrm{ac}}\right)$ that is ultimately fixed by the hydrocarbon-chain area is less than the maximum possible interchain distance allowed for a given lanthanide element, i.e., $d_{\mathrm{ac}} \leq d_{\max }$.

It is remarkable that from this analysis we can predict that lanthanides with $\mathrm{M}-0$ distance greater than about $2.64 \AA$ (from the intersection of lower SmA1 and $d_{\max }$ curve) can comfortably form a 2D MOF mesophase, like the smectic SmA1, and those below cannot. Indeed, the range of $\mathrm{Nd}-\mathrm{O}$ distances in the analogous Nd-butyrate monohydrates of Binnemans et al. [47**], span from 2.42-2.66 $\AA$, and they observe that Nd soaps sometimes form the SmA1 mesophase and sometimes do not. Samarium and europium soaps are also borderline cases under this analysis (in fact europium soap mesophases have been reported in one study) [89].

Further, the curve indicating the lower limit of the SmB stability intersects at about $2.44 \AA$, and therefore predicts that the $\mathrm{SmB}$ phase is a 2D MOF, and incorporates lanthanides as small as $\mathrm{Yb}(\mathrm{Yb}-\mathrm{O}$ ranges from 2.28-2.59 $\AA$ in Yb succinate hydrate [90]). However, given the heaviest lanthanides can have Ln-O distances below $2.44 \AA$, we might predict that, say, Ho-Lu soaps may form SmB phases comprised of

Table 2

Area-per-chain $\left(\AA^{2}\right)$ for the various phases close to the lower temperature bound

\begin{tabular}{|c|c|c|c|c|c|}
\hline $\mathrm{Cr}$ & $\mathrm{CrB}$ & $\mathrm{SmB}^{*}$ & SmA1 & Melt & Melt \\
\hline 18.9-19.3 & $19.7-20.6 \AA^{2}$ & $21.0-21.8$ & $24.3-25.3$ & $(\mathrm{Sm}-\mathrm{Yb}): 24.2-24.4$ & (La-Pr): 25.5-26.6 \\
\hline
\end{tabular}

*Estimated using subcell $d$-spacing in laurate samples quenched to room temperature. 


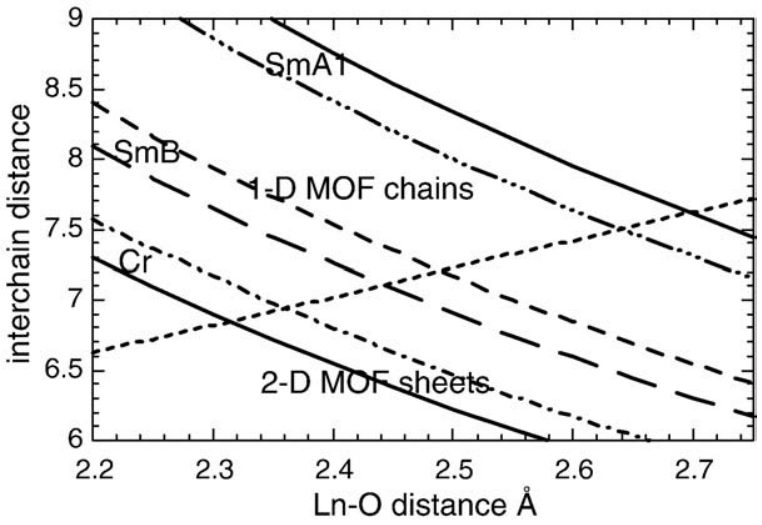

Fig. 13. Topological phase space for the lanthanide soaps. Chain separation is plotted as a function of Ln-O distance. Lower and upper limits of the respective phases are plotted as lines (dots, dashes and solids, falling to the right). The dotted line (rising to the right) is the maximum possible allowed chain separation for a 2D MOF. This analysis predicts all lanthanide soaps can crystallize as 2D MOFs, and form mesophases with both 2D and 1D MOF polar layers.

unstable 2D MOFs or strongly interacting 1D MOFs (this may be the case for lanthanide soaps that show a large splitting of the main melting endotherm, and have a lower viscosity SmB phase, e.g., $\mathrm{Yb}$ stearate).

Finally, the upper limit of the SmA1 curve indicates that the following (low viscosity) mesophase, the SmA2 mesophase, probably consists of layers of 1D MOF's, since the intersection occurs at $2.70 \AA$, and the range of Ln-O distances in lanthanum butyrate[63*'] spans from 2.47-2.71

\section{High-temperature cubic strontium myristate as a MOF mesophase}

Here is a short test to prove if a branched MOF network can be fitted to one of the classical metal soaps structures - the Ia3d cubic mesophase of strontium myristate [18*0], as this would further demonstrate the benefits of viewing liquid-crystalline metal soaps as MOF mesophases.

Luzzati et al. [18**] published the remarkable mesostructure of the anhydrous strontium myristate liquid-crystalline $\left(225^{\circ} \mathrm{C}\right)$ phase. They reported 13 peaks and used these to positively identify the space group as Ia3d. Their computational model includes a locus of Sr atoms as finite length, infinitely thin rods on two-fold axes joined at threeway junctions to form bicontinuous interpenetrating networks. They modeled the diffraction data best (using 24 rods per unit cell) when the electron density of $\mathrm{Sr}$ atoms was distributed uniformly along the rods and leaving short gaps at the end of the rods. Luzzati et al. showed that that the number of $\mathrm{Sr}$ atoms per rod stayed constant at ca. $0.5 \AA^{-1}$ as the fatty acid chains became longer (i.e., laurate through stearate). For the myristate they found this to be very close to $10 \mathrm{Sr}$ atoms per rod unit, or just short of $240 \mathrm{Sr}$ atoms per unit cell (actually 233). They noted that the linear density was independent of chain length, and temperature, as previously seen in other alkali earth metal soaps. Displacement of $\mathrm{Sr}$ atoms from the symmetry axes is supported by their data, but disorder and thermal fluctuations meant that atomic position data in the polar groups were beyond the resolution of their structure determination.

The relatively fixed linear cation densities Luzzati et al. found on each of the 24 rods in the cubic (and rhombohedral and mesh) unit cells of homologous strontium soaps (and in the hexagonal phase) is approximately twice that found for the linear density of $\mathrm{Sr}$ atoms along edge (and some face) sharing $\mathrm{SrO}_{n}$ polyhedra $(n=7-8)$ in $\mathrm{Sr}$ carboxylates (acetates, maleate) [91,92]. This suggests that two interpenetrating branched coordination polymers can be mapped with their long axes coincident with the rod axes of Luzzati et al.'s structure to obtain an atomistic model of the cubic strontium soap mesophase that is consistent with the rod dimensions, number of atoms per unit cell, etc. This can be tested by showing the existence of a branched coordination polymer with realistic bond angles and lengths and consistent with the space group Ia3d. Admittedly such a static structure would not be completely representative since disorder and motion (of hydrocarbon chains and polar rods) will fluctuate through the liquid crystal, breaking the local symmetry.

Two such models were generated. The metal-oxygen polyhedral rods are constructed manually (atom-by-atom placement) with trialand-error used to obtain reasonable bond angles and distances. In the first case (Fig. 14A,B) these are edge and vertex sharing, in the second, they are only edge sharing (Fig. 15A,B). The two models have a cubic unit cell of $a=62.6 \AA$, with 240 strontium atoms and 960 oxygen atoms per unit cell. $\mathrm{Sr}$ is in 6-coordination in both (as in the coordination in

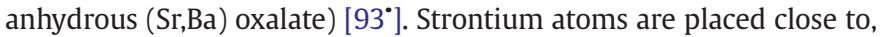
but not on, the rods defined by Wyckoff position $48 \mathrm{~g}(x, 0,0.25)$. The coordinates are given in the supplementary materials section. The polyhedral rods are comprised of edge sharing, distorted octahedra, joined at the three-fold axes by bridging carboxylates, and have long
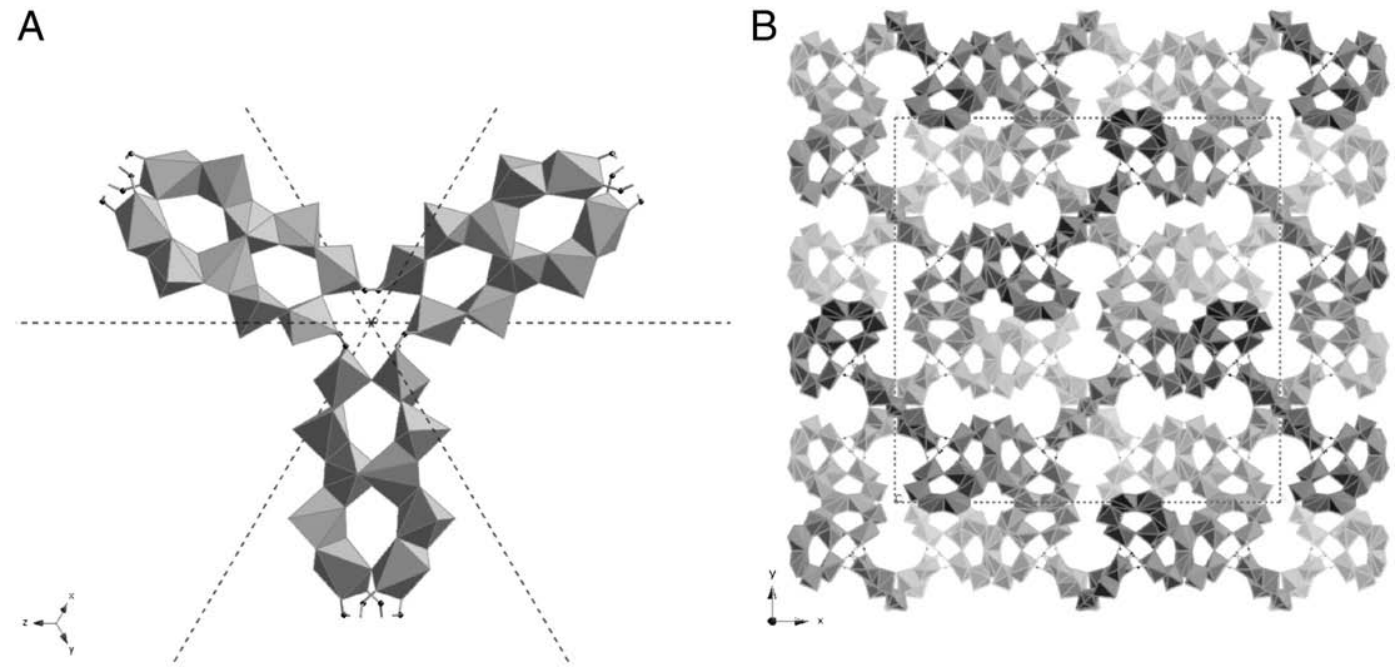

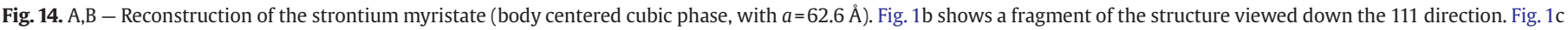

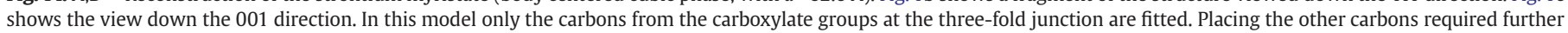
distortions of the polyhedra, and this is shown in Fig. 15A,B. 
axes running down their centers of mass that map onto the rod network of Luzzati et al.

Both structures give simulated powder diffraction patterns in good agreement with Luzzati et al.'s original intensity data (judged by summing the square of the residuals of observed minus modeled intensity per reflection - for both Luzzati et al.'s model and the present models versus Luzzati et al.'s original intensity data). The calculated density for strontium myristate (using 233 molecules per unit cell, and both models) is in agreement with the observed density reported by Luzzati et al.: $\rho_{\text {calc }}=0.8554 \mathrm{~g} \mathrm{~cm}^{-3} ; \rho_{\text {obs }}=0.85(8) \mathrm{g} \mathrm{cm}^{-3}$.

It is possible that there could be higher-coordinate face-sharing solutions, but given the existence of $\mathrm{Sr}-\mathrm{Ba}$ oxalate [93*]with 6coordinate $\mathrm{Sr}$, it seems these models, particularly the latter, give a reasonable, atomically resolved fit to the $\mathrm{Sr}$ myristate cubic liquidcrystalline phase. Indeed these structures have a more than passing resemblance interpenetrating MOFs $\left[94^{*}, 95\right]$.

Rhombohedral, tetragonal and hexagonal mesophases of the alkaline earth soaps were also modelled by Luzzati et al. using rod structures and found to have the same or very similar cation densities (along the rods). Therefore it now appears likely that these, and perhaps most, if not all, metal soap mesophases are comprised of
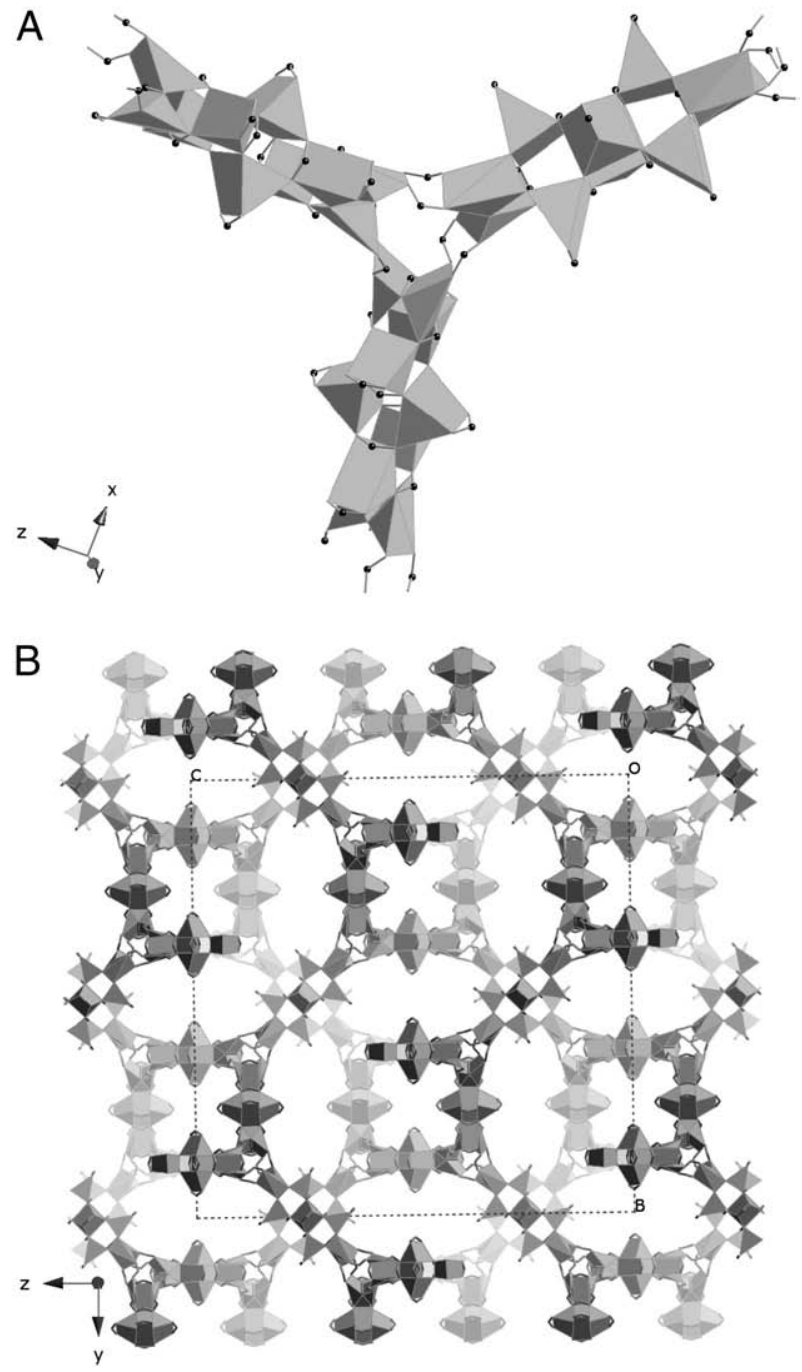

Fig. 15. A,B - Reconstruction of the strontium myristate (body centered cubic phase, with $a=62.6 \AA$ ). This alternative model has more highly distorted polyhedra, but contains all carbons placed under Ia3d symmetry, and with the orientation of the polyhedra more favourable for a symmetric filling of the remaining space by conformationally disordered chains. This model also gives better intensity residuals than the model in Fig. 14A,B. similar MOFs. For example, it seems reasonable that the higher temperature hexagonal phase in the strontium soaps is comprised of infinite 1D MOFs similar to infinitely long versions of the shorter rods in the cubic phase.

Furthermore, the concept of a bicontinuous 3D liquid-crystalline MOF is easily extended to theoretical construction of multi-continuous 3D MOF's (liquid crystalline or not), and indeed simple constructions have been made that confirm this. Thus a challenge is issued to experimentalists to find such a structure. Multi-continuous networks have been discussed by Hyde et al. [96].

\section{Conclusions}

A substantial body of literature is now available to suggest that the crystal structures of metal soaps are analogous to their lighter-weight, shorter-chain analogs including diacid soaps. This gives a picture of metal soaps of saturated long-chain fatty acids as lamellar crystals with chains in the all-trans state, pointing out and away from MOF polar layers. These MOF layers are comprised of 1D or 2D coordination polymers.

These evidences for the crystal structures of metal soaps constrain the initial bond topologies and geometries critical for the analysis of subsequent phase transformations to liquid crystals. The likely structure for the classic calcium stearate monohydrate then follows from the calcium adipate monohydrate structure. Likewise, the crystal structure soaps of the hydrated lighter, larger lanthanides are most likely arranged in 2D sheets made up from carboxylate-bridged, edgesharing 1D MOFs.

During thermotropic phase transformation of the lanthanide soaps, the initially crystalline state transforms through various degrees of dehydration and molecular disordering prior to final chain melting. The transitions initially involve a gradual loosening of the chain packing, along with a gradual loosening of the 2D MOF structure, which is probably highly ordered in the hydrated crystalline soaps.

Experimental evidence and modelling points to the anhydrous and hydrated lanthanide soaps as 2D MOFs at room temperature. During heating, the chains and MOF headgroups gradually expand and transition through increased rotational and conformational disorder to either 2D smectic rotor-phase MOFs, 2D liquid-crystalline smectic MOFs or 1D liquid-crystalline smectic MOFs. The MOF headgroup layers and the hydrocarbon chains display both dependent and semiindependent degrees of ordering and disordering. For hydrated lanthanide soaps, the relatively large enthalpy of dehydration acts to broaden the temperature range from crystal to liquid and also emphasizes and demarcates the subtle rearrangements in the 2D and 1D MOF networks that trigger and control the temperature and rate at which dehydration begins and ends.

Distinction between the phase transformations of soaps of larger and smaller lanthanide ions can be readily predicted by modelling the soaps as sheets of 1D MOFs and testing if metal-carboxylate crosslinks can polymerise the sheets into 2D MOFS or not. The interfacial area of the chains set the distances that the metal-carboxylate bonds must bridge, and it appears that both 1D and 2D polymerised MOFs are predicted to display thermotropic liquid crystals under these constraints.

Finally, two interpenetrating 3D MOF models for the bicontinuous Ia3d cubic mesophase of strontium soaps are constructed. These contribute an improved conception and resolution of the metal organic carboxylate framework in Luzzati et al.'s original interpenetrating rod structure. This demonstrates the possibility of modelling structures other than 1D and 2D using the MOF concept for metal soaps, and is a predictor for other MOFs liquid crystals containing more complicated topologies such as multi-continuous MOF liquid crystals.

Metal soaps thus provide a previously unreported bridge between liquid crystals and metal organic framework (MOF) structures. 


\section{Appendix A. Supplementary data}

Supplementary data associated with this article can be found, in the online version, at doi:10.1016/j.cocis.2008.03.001.

\section{References and recommended reading,$\cdots$}

[1] Heintz W. Über die fette. J Prakt Chem 1855;66:1-51.Arguably the first report of liquid crystallinity in metal soaps

[2] Vorländer D. Verhalten der Slaze organischer Säuren beim Schmelzen. Chem Ber 1910;43:3120-35.

[3] Walter R. Über krystallinisch- flüssige. Chem Ber 1926;59:962-72.

[4] McBain JW, Field MC. Phase-rule equilibria of acid soaps. Par II. Anhydrous acid sodium palmitates. J Chem Soc 1933:920-4

[5] McBain JW, Stewart A. Phase-rule equilibria of acid soaps. Part III. Anhydrous acid potassium oleate. J Chem Soc 1933:924-8.

[6] Thiessen PA, Stauff J. Feinbau und Umwandlungen kristallisieter Alkalisalze langkettinger Fettsäuren. Z Phys Chem 1936;176:397-429.

[7] Hermann K. Inclinations of molecules in some crystalline fluid substances. Z Kristallogr 1935:92:49-81.

[8] Vold RD, Vold MJ. Successive phases in the transformation of anhydrous sodium palmitate from crystal to liquid. J Am Chem Soc 1939;61:808-16.

[9] Chesley F. An X-ray investigation of the phase transitions of sodium palmitate. J Chem Phys 1940;8:643.

[10] de Bretteville AJ. High temperature X-ray camera. J Appl Phys 1943;14:137.

[11] Bolduan OEA, McBain JW, Ross S. Diffraction of X-rays by sodium laurate and palmitate. J Phys Chem 1943:47:535.

[12] Nordsieck H, Rosevear FB, Ferguson RH. An X-ray study of the stepwise melting of anhydrous sodium palmitate. J Chem Phys 1948;16:175-80.

[13] Hattiangdi GS, Vold MJ, Vold RD. Differential thermal analysis of metal soaps. Ind Eng Chem 1949;41:2320-4.

[14] Hartley GS. Aqueous solutions of paraffin chain salts. Paris: Hermann; 1936. important early paper on the molten state of hydrocarbon chains in lipidic mesophases

[15̣] Schmitt FO, Bear RS, Palmer KJ. X-ray structure of nerve myelin. J Cell Comp Physiol $1941 ; 18: 31$.An important early paper on the molten state of hydrocarbon chains in biomembranes

[16] Luzzati V, Tardieu A, Gulik-Krzywicki T, Rivas E, Reiss-Husson F. Structure of the cubic phases of lipid-water systems. Nature 1968;220:485-8.

[17] Luzzati V, Tardieu A, Gulik-Krzywicki T. Polymorphism of lipids. Nature 1968;217:1028-30.

[18] Luzzati V, Spegt P. Polymorphism of lipids. Nature 1967;215:701-4.One of the earliest descriptions of interpenetrating metal organic frameworks in the strontium soap liquid crystalline system

[19] Adeosun SO, Sime SJ. Properties of molten carboxylates. Part 4: a quantitative differential thermal analysis study of melting and mesophase formation in some lead(II) carboxylates. Thermochim Acta 1976;17:351-9.

[20] Meisel T, Seybold K, Halmos Z, Roth J, Melykuti C. Thermal behaviour of thallium(I) fatty acid salts. J Therm Anal 1976;10:419-31.

[21] Höhne U, Möhwald H. The influence of counterions and hydrophobic moieties on the thermostability of Langmuir-Blodgett multilayers. Thin Solid Films 1994;243:425-30.

[22] Bée M, Giroud-Godquin AM, Maldivi P, Williams J. Incoherent quasi-elastic neutron scattering study of highly oriented fibres of copper laurate in the columnar mesophase. Mol Phys 1994;81:57-68.

[23] Giroud-Godquin AM, Maitlis PM. Metallomesogens: metal complexes in organised fluid phases. Angew Chem Int 1991;30:375-402.

[24] Baena MJ, Espinet P, Lequerica MC, Levelut AM. Mesogenic behaviour of silve thiolates with layered structure in the solid state: covalent "soaps". J Am Chem Soc 1992;114:4182-5.

[25] Johnson DJ, Amm DT. Order-disorder transitions of yttrium arachidate LangmuirBlodgett films via ellipsometric anisotropies. Thin Solid Films 1994;247:120-8.

[26] Seghrouchni R, Skoulios A. Columnar to nematic mesophase transitions: binary mixtures of unlike copper soaps. J Phys II France 1995;5:1547-65.An unusual nematic mesophase in the copper carboxylate system is reported

[27] Merle HJ, Steitz R, Pietsch U, Peterson IR. The lamellar-columnar transition in Langmuir-Blodgett multilayers of cadmium soaps. Thin Solid Films 1994;237: 236-43.

[28] Redondo MI, García MV González-Tejera MJ Cheda JAR. Spectroscopic study of the phase transitions of copper(II) $n$-alkanoates. Spectrochim Acta 1995;51A:341-7.

[29] Mahler W, Baberka TA, Pietsch U, Höhne U, Merle HJ. Thermally-induced phase transitions in LB multilayers of lead stearate. Thin Solid Films 1995;256: 198-204.

[30] Peng JB, Foran GJ, Barnes GT, Gentle IR. Phase transitions in Langmuir-Blodgett films of cadmium stearate: grazing incidence X-ray diffraction studies. Langmuir 1997;13:1602-6.

[31] Bonnet L, Cukiernik FD, Maldivi P, Giroud-Godquin AM, Marchon JC. Synthesis, Xray diffraction, differential scanning calorimetry, and magnetic susceptibility studies of a series of binuclear ruthenium(II) carboxylates givings liquidcrystalline phases. Chem Mater 1994;6:31-8.

\footnotetext{
- Of special interest.
}

[32] Baxter DV, Cayton RH, Chisolm MH, Huffman JC, Putilina EF, Tagg SL, Wesemann JL, Zwanziger JW, Darrington FD. Multiple bonds between metal atoms in ordered assemblies. 2. Quadruple bonds in the mesomorphic state. J Am Chem Soc 1994;116:4551-66

[33] Ibn-Elhaj M, Guillon D, Skoulios A, Giroud-Godquin AM, Maldivi P. Structural study of crystalline and columnar copper (II) soaps. Liq Cryst 1992;11:731-44.

[34] Garbovskiy Y, Koval, apos, chuk A, Grydyakina A, Bugaychuk S, Mirnaya T, Klimusheva G. Electrical conductivity of lyotropic and thermotropic ionic liquid crystals consisting of metal alkanoates. Liq Cryst 2007;34:599-603.

[35] Adeosun SO, Sime WJ, Sime SJ. Properties of molten carboxylates. Part 3. Electrical conductance, density and viscosity of some molten cadmium carboxylates. Faraday Trans 1 1976;72:2470-6.

[36] Lawrence ASC. Metal soaps and gelation of paraffin solutions. Trans Faraday Soc 1938;34:660-77* A systematic early study recording thermotropic mesomorphism in metal soaps.

[37] Boner CJ. Metallic soaps for thickening mineral oils. Ind Eng Chem 1937;29:58-60.

[38] Mehrotra KN, Shukla RK, Chauhan M. Spectroscopic and conductometric studies of lanthanide soaps. Bull Chem Soc Jpn 1995;68:1825-31.

[39] Mehrotra KN, Gahlaut AS, Sharma M. Infrared, thermal and X-ray diffraction studies on lanthanum soaps. J Indian Chem Soc 1987;64:309-10.

[40] Mehrotra KN, Gupta S. Conductometric and viscometric studies of gadolinium soaps. J Indian Chem Soc 1993;70:577-9.

[41] Mehrotra KN, Anis M. Ultrasonic and viscometric studies of samarium laurate in benzene dimethylsulfoxide mixtures. Monatsh Chem 1995;126:637-45.

[42] Marques EF, Burrows HD, da Graca Miguel M. The structure and thermal behaviour of some long chain cerium(III) carboxylates. Faraday Trans 1998;94:1729-36.A significant and comprehensive study on cerium soaps and their smectic mesophases

[43] Jongen L, Binnemans K, Hinz D, Meyer G. Thermal behaviour of lanthanum(III) alkanoates. Liq Cryst 2001;28:1727-33.

[44] Jongen L, Binnemans K, Hinz D, Meyer G. Mesomorphic behaviour of cerium(III) alkanoates. Mater Sci Eng C 2001;18:199-204.

[45] Jongen L, Binnemans K, Hinz D, Meyer G. Mesomorphic behaviour of praseodymium(III) alkanoates. Liq Cryst 2001;28:819-25.

[46] Binnemans K, Jongen L, Görller-Walrand C, D'Olieslager W, Hinz D, Meyer G. Lanthanide(III) Dodecanoates: structure, thermal behaviour, and ion-size effects on the mesomorphism. Eur J Inorg Chem 2000:1429-36.The first comprehensive study on lanthanide soaps and their thermotropic mesophase behavior across the period

[47] Binnemans K, Jongen L, Bromant C, Hinz D, Meyer G. Structure and mesomorphism of Neodymium(III) alkanoates. Inorg Chem 2000;39:5938-45.Key paper in understanding the MOF headgroup structure of hydrated lanthanide soaps

[48] Binnemans K, Heinrich B, Guillon D, Bruce DW. Preliminary communication on the mesomorphism of lanthanum(III) alkanoates. Liq Cryst 1999;26:1717-21.The first in a definitive series of papers from the Binnemans group describing smectic mesophases in the lanthanide soaps

[49] Li H, Bu W, Qi W, Wu L. Self-assembled multibilayers of europium alkanoates: structure, photophysics and mesomorphic behavior. J Phys Chem 2005; B109:21669-76.

[50] Bylina DV, Mirnaya TA, Volkov SV. Phase diagrams of liquid-crystal binary systems of lanthanum(III) laurate with some divalent metal laurates. Russ J Inorg Chem 2006;51:639-41.

[51] Cingolani A, Spinolo G, Sanesi M, Franzosini P. On the thermal behaviour of the C13-C20 potassium alkanoates. Z Naturforsch 1980;35a:757-65.

[52] Corkery RW. A variation on Luzzati's soap phases. Room temperature thermotropic liquid crystals. Phys Chem Chem Phys 2004;6:1534-46.Describes room temperature hexagonal mesophases of many metal soaps, including the lanthanide soaps of branched-chain fatty acids

[53] Corkery RW. Artificial biomineralisation and metallic soaps [PhD]: Australian National University: 1998. ** The present author's comprehensive review and experimental study of more than 100 distinct metal soap systems.

[54] Guo XD, Zhu GS, Li ZY, Sun FX, Yang ZH, Qiu SL. A lanthanide metal-organic framework with high thermal stability and available Lewis-acid metal sites. Chem Comm 2006:3172-4.

[55] Millward AR, Yaghi OM. Metal-organic frameworks with exceptionally high capacity for carbon dioxide at room temperature. J Am Chem Soc 2005;127:17998-9.

[56] Yaghi OM, O'Keeffe M, Ockwig NW, Chae HK, Eddaoudi M, Kim J. Reticular design and the synthesis of new materials. Nature 2003:423:705-14.

[57] Ockwig NW, Delgado-Friedrichs O, O'Keeffe M, Yaghi OM. Reticular chemistry: Occurrence and taxonomy of nets and grammar for the design of frameworks. Acc Chem Res 2005;38:176-82 ** Succinct paper on the rules of metal organic framework construction.

[58] Kim J, Chen BL, Reineke TM, Li HL, Eddaoudi M, Moler DB, O'Keeffe M, Yaghi OM. Assembly of metal-organic frameworks: structure design and sorption properties. J Am Chem Soc 2001;123:8239-47.

[59] Eddaoudi M, Moler DB, Li HL, Chen BL, Reineke TM, O'Keeffe M, Yaghi OM. Secondary building units as a basis for the design of highly porous and robust metal-organic carboxylate frameworks. Acc Chem Res 2001;34:319-30.

[60] Cheetham AK, Rao CNR, Feller RK. Structural diversity and chemical trends in hybrid inorganic-organic framework materials. Chem Comm 2006:4780-95. Structuro-chemical review discussing a diverse range of metal organic framework materials

[61] Lossin A, Meyer G. Anhydrous rare-earth acetates, $\mathrm{M}(\mathrm{CH} 3 \mathrm{COO}) 3(\mathrm{M}=\mathrm{Sm}-\mathrm{Lu}, \mathrm{Y})$ with chain structures - crystal structures of $\mathrm{Lu}(\mathrm{CH} 3 \mathrm{COO}) 3$ and $\mathrm{Ho}(\mathrm{CH} 3 \mathrm{COO}) 3$. Z Anorg Allg Chem 1993;619:1609-15. 
[62] Lossin A, Meyer G. $\operatorname{Pr}(\mathrm{CH} 3 \mathrm{COO}) 3$, an anhydrous rare-earth acetate with a network structure. Z Anorg Allg Chem 1994;620:438-43.

[63] Jongen L, Meyer G, Binnemans K. Crystal structure of lanthanum(III) butyrate monohydrate. J Alloy Comp 2001;323-324:142-6.Key paper for understanding the MOF headgroup structure of hydrated lanthanide soaps

[64] Lelann P, Berar JF. Synchrotron high-resolution powder study of molecular packing in hydrated calcium stearate. Mater Res Bull 1993;28:329-36.

[65] Mathew M, Takagi S, Ammon HL. Crystal-structure of calcium adipate monohydrate. J Crystallogr Spectrosc Res 1993;23:617-21.Describes the only fully solved calcium carboxylate crystal structure homologous to crystalline hydrated calcium stearate

[66] Lacouture F, Peultier J, François M, Steinmetz J. Anhydrous polymeric zinc(II) octanoate. Acta Crystallogr 2000;C56:556-7.

[67] Blair J, Howie RA, Wardell JL. Structure of monoclinic zinc-n-butanoate. Acta Crystallogr 1993;C49:219-21.A short-chain analog of long-chain anhydrous zinc soaps

[68.] Peultier J, François M, Steinmetz J. Anhydrous polymeric zinc(II) heptanoate. Acta Crystallogr 1999;C55:2064-5.One of very few medium-chain analogs of a metal soap - providing significant insight into the headgroup structure of anhydrous zinc soaps. Also see Ref. 66

[69] Ghermani NE, Lecomte C, Rapin C, Steinmetz P, Malaman B. Structure and preliminary electron distribution of copper heptanoate from room-temperature X-ray data. Acta Crystallogr 1994;B50:157-60.

[70] Plater MJ, de Silva B, Gelbrich T, Hursthouse MB, Higgitt CL, Saunders DR. The characterisation of lead fatty acid soaps in 'protrusions' in aged traditional oil paint. Polyhedron 2003;22:3171-9.

[71] Lomer TR, Perera K. Anhydrous copper(II) decanoate. Acta Crystallogr 1974; B30:2912-3.

[72] Lomer TR, Perera K. Anhydrous copper(II) octanoate. Acta Crystallogr 1974: B30:2913-5.Probably the first fully resolved crystal structure for a metal soap, showing the classic paddle wheel $\mathrm{Cu}(\mathrm{II})-\mathrm{Cu}(\mathrm{II})$ dimer known earlier from $\mathrm{Cu}$ (II) acetate structure. Also see Ref 71

[73] Taylor RA, Ellis HA, Maragh PT, White NAS. Room temperature structures of anhydrous zinc(II) hexanoate and pentadecanoate. J Mol Struct 2006;787:113-20 One of very few reports of atomically resolved, long-chain anhydrous metal soap.

[74] Rueff JM, Masciocchi N, Rabu P, Sironi A, Skoulios A. Synthesis, structure and magnetism of homologous series of polycrystalline cobalt alkane mono- and dicarboxylate soaps. Chem Eur J 2002;8:1813-20. Reports crystal structures of hydrated cobalt soaps from powder and selected area X-ray diffraction.

[75] Tolochko BP, Chernov SV, Nikitenko SG, Whitcomb DR. EXAFS determination of the structure of silver stearate, $\left[\mathrm{Ag}\left(\mathrm{O}_{2} \mathrm{C}\left(\mathrm{CH}_{2}\right) 16 \mathrm{CH}_{3}\right] 2\right.$, and the effect of temperature on the silver coordination sphere. Nucl Instrum Methods Phys Res Sect A-Accel Spectrom Detect Assoc Equip 1998;405:428-34.Demonstration of the usefulness of EXAFS in determination of metal-oxygen framework topology in metal soaps

[76] Corkery RW. Lanthanide contraction in crystalline 2D metal organic framework materials (MOFS). To be published 2008.

[77] Vold RD, Hattiangdi GS. Characterisation of heavy metal soaps by X-ray diffraction. Ind Eng Chem 1949;41:2311-20.Comprehensive early X-ray diffraction study of metal soaps
[78] Spegt P, Skoulios A. Contribution a l'etude comparative de la structure lamellaire des savons de certains metaux alcino-terreux a des temperatures inferieures a $120{ }^{\circ} \mathrm{C}$. J Chim Phys 1965:418-22.

[79] Abrahamsson S, Dahlén B, Löfgren H, Pascher I. Lateral packing of hydrocarbon chains. Prog Chem Fats Other Lipids 1978;16:125-43.Key paper in understanding the structure and diversity of chain-packing modes in lipids and lipid-like crystals

[80] Larsson K. Lipids - molecular organisation, physical functions and technical applications edn 1st. Dundee: The Oily Press; 1994.One-stop review of lipid structures and their phase behaviors

[81] Corkery RW. Langmuir-Blodgett (L-B) multilayer films. Langmuir 1997;13:3591-4

[82] Pascher I, Lundmark M, Nyholm PG, Sundell S. Crystal structures of membrane lipids. Biochim Biophys Acta 1992;1113:339-73.Authoritative work on the crystal structure of lipids

[83] Skoulios A, Luzzati V. Structure of anhydrous sodium soaps at high temperatures. Nature 1959;183:1310-2.The first paper in the series of papers by Luzzati et al. on thermotropic msomorphism in soaps

[84] Corkery RW, Rousseau D, Smith P, Pink DA, Hanna CB. A case for discotic liquid crystals in molten triglycerides. Langmuir 2007;23:7241-6.

[85] Ellis HA. Thermotropic phase transitions in some lead(II) carboxylates. Mol Cryst Liq Cryst 1986;139:281-90.

[86] Adeosun SO, Sime SJ. The properties of molten carboxylates: Part 7. Odd-even variation in melting and mesophase formation in the lead(II) carboxylates. Thermochim Acta 1978;27:319-27.

[87] Adeosun SO. Electrical conductance and thermal behaviour of some manganese(II) carboxylates. Can J Chem 1979;57:151-6.

[88] Masuda Y. Thermal decomposition of formates. Part VIII. Thermal dehydration of $\mathrm{Dy}(\mathrm{III}), \mathrm{Ho}(\mathrm{III}), \mathrm{Er}(\mathrm{III}), \mathrm{Tm}(\mathrm{III}), \mathrm{Yb}(\mathrm{III})$ and $\mathrm{Lu}(\mathrm{III})$ formate dihydrates. Thermochim Acta 1983;60:203-10.

[89] Li H, Bu W, Oi W, Wu L. Self-assembled multibilayers of europium alkanoates: struc ture, photophysics and mesomorphic behavior. J Phys Chem B 2005;109:21669-76.

[90] Rahahlia N, Alioune K, Guehria-Laidoudi A, Dahaoui S, Lecomte C. Poly [[tetraaquadi-m4-succinato-m5-succinato-diytterbium(III)] hexahydrate]. Acta Crystallogr Section E 2006;62:m2543-5.

[91] Lengauer CL, Giester G. Strontium acetate nitrate trihydrate $\left[\mathrm{Sr}_{2}\left(\mathrm{CH}_{3} \mathrm{COO}\right)_{2}\left(\mathrm{NO}_{3}\right)_{2}\right.$ $\left(\mathrm{H}_{2} \mathrm{O}\right)_{3}$ ]. Acta Crystallogr 1997;C53:870-2.

[92] Díaz de Delgado G, Parra PP, Briceno A, Delgado M. Crystal structure of triaquamaleatostrontium(II) monohydrate, $\left[\mathrm{Sr}\left(\mathrm{C}_{4} \mathrm{H}_{2} \mathrm{O}_{4}\right)\left(\mathrm{OH}_{2}\right)_{3}\right] \mathrm{H}_{2} \mathrm{O}$. J Chem Crystallogr 2005;25:1572-8854

[93] Trifa C, Bouhali A, Boudaren C, Bouacida S, Bataille T. Anhydrous barium strontium oxalate. Acta Crystallogr, Section E: Structure Reports Online 2007;63:i102-4.A rare, if not unique crystal structure solution for an anhydrous alkali earth metal carboxylate

[94] Li H, Eddaoudi M, O'Keeffe M, Yaghi OM. Design and synthesis of an exceptionally stable and highly porous metal-organic framework. Nature 1999;402:276.First paper describing the systematic synthesis and design of metal organic framework (MOF) structures

[95] Chen B, Eddaoudi M, Hyde ST, O'Keeffe M, Yaghi OM. Interwoven metal-organic framework on a periodic minimal surface with extra-large pores. Science 2001;291:1021-3.

[96] Hyde ST, Ramsden S, DiMatteo T, Longdell JJ. Ab-initio construction of some crystalline 3D Euclidean networks. Solid State Sci 2003;5:35-45. 